\title{
Co-Al spinel-based nanoparticles synthesized by flame spray pyrolysis for glycerol conversion
}

\author{
A. Lähde ${ }^{1, \S}$,R. J. Chimentão ${ }^{2,3, \S}$, T. Karhunen ${ }^{1}$, M. G. Álvarez ${ }^{3}$, J. Llorca ${ }^{4}$, F. Medina ${ }^{3}$, J. Jokiniemi ${ }^{1}$ \\ L.B. Modesto-López, \\ ${ }^{1}$ Department of Environmental Science, University of Eastern Finland, FI-70211, Kuopio, Finland \\ ${ }^{2}$ Departament of Physical Chemistry, Faculty of Chemistry Science, Universidad de Concepción, \\ Casilla 160-C, Concepción, Chile \\ ${ }^{3}$ Department of Chemical Engineering, Universitat Rovira i Virgili, Av. Països Catalans 26, ES-43007, \\ Tarragona, Spain \\ ${ }^{4}$ Institute of Energy Technologies, Department of Chemical Engineering and Barcelona Research \\ Center in Multiscale Science and Engineering. Universitat Politècnica de Catalunya, EEBE, 08019 \\ Barcelona, Spain \\ ${ }^{5}$ Department of Aerospace Engineering and Fluid Mechanics, University of Seville, Camino de los \\ Descubrimientos s/n, ES-41092, Seville, Spain \\ $\S$ These authors contributed equally \\ *Corresponding author: lmodesto@us.es
}

Phone number: $+34(954) 48-7224$ 


\begin{abstract}
The catalytic properties of Co-Al spinel nanoparticles prepared by liquid-feed flame spray pyrolysis (LF FSP) were investigated in the glycerol conversion in gas phase in an atmosphere of hydrogen. Reduction at $1123 \mathrm{~K}$ of the as-synthesized spinel nanoparticles induced the formation a new phase containing metallic cobalt species. Although, the reducibility of cobalt oxides is greatly decreased due to interaction with aluminium species, this strong interaction may prevent the aggregation of Co particles under the harsh reduction conditions. X-ray photoelectron spectroscopy (XPS) of the reduced spinel nanoparticles at $1123 \mathrm{~K}$ revealed that the $\mathrm{Co} / \mathrm{Al}$ atomic ratio has decreased to $\mathrm{Co} / \mathrm{Al}=0.11$, which may indicate a redistribution of the aluminum and cobalt species at the surface of the sample submitted to the reduction in a flow of hydrogen at $1123 \mathrm{~K}$. X-ray diffraction (XRD) and high resolution electron microscopy (HRTEM) also reinforced the formation of metallic cobalt species after reduction of cobalt from the spinel nanoparticles at $1123 \mathrm{~K}$. The main products obtained from the conversion of glycerol in the gas phase were hydroxyacetone, pyruvaldehyde, lactic acid and lactide. FSP successfully gave insights to ensure uniform dispersion of the active metal on a support material.
\end{abstract}

Keywords: flame spray pyrolysis, catalyst, cobalt, nanoparticles, glycerol conversion 


\section{Introduction}

Glycerol is an extremely versatile building block within biorefineries as it offers many opportunities for production of useful chemicals. Nearly two-thirds of the world's glycerol production comes as byproduct from biodiesel. Furthermore, biodiesel production increased rapidly from 1 million tons in 2000 to 25 million tons in 2015 [ $1-3]$. Thus, the availability of glycerol is expected to increase as the demand for biodiesel continues to rise globally. Hence, the transformation of glycerol into valuedadded products and commodity chemicals has been intensively studied over the last decade [2].

The transformation of glycerol by catalytic conversion is often carried out using noble metal-based catalysts for hydrogen activation. Conversely, transition metal-based materials are alternative catalysts for glycerol transformation [5-7]. Despite their lower activity for hydrogenation compared to noble metals they present other advantages, such as much lower prices and higher resistance to poisoning [8].

In addition to the kind of metal for the catalyst other features must be considered when selecting a material namely, the size of the metal particle, the type and morphology of the support, and the homogeneity of the catalyst and the metal dispersion. Numerous studies have shown that particle size and dispersion of the metal play a major role in the selectivity of catalytic reactions [7]. The dispersion, defined as the fraction of the atoms in a cluster present on the catalyst surface, depends on the conditions of preparation, approaching unity when these metallic clusters are extremely small of the order of $1 \mathrm{~nm}$ in size [8]. The control of the size of metal nanostructures may thus provide powerful a method to enhance the catalytic activity of metal particles [9]. 
Cobalt is one of the most attractive transition metals used in catalytic reactions owing to its availability and relatively low cost [10]. Typically, for heterogeneous catalysis, Co/alumina particles are prepared by using either solid state reactions of their parent oxides $\left(\mathrm{Co}_{3} \mathrm{O}_{4}\right.$ and $\left.\gamma-\mathrm{Al}_{2} \mathrm{O}_{3}\right)$ or by wet methods (e.g. impregnation, sol-gel process) followed by their thermal treatment in air [11, 12]. However, $\mathrm{Co}_{3} \mathrm{O}_{4}$ and $\gamma-\mathrm{Al}_{2} \mathrm{O}_{3}$ have isotype crystal structures that enable the migration of ions from cobalt oxide into the underlying alumina support, thus forming aluminate spinels (e.g., $\mathrm{Co}_{2} \mathrm{AlO}_{4}, \mathrm{CoAl}_{2} \mathrm{O}_{4}$ ) when heated. It has been suggested that cobalt ions occupying surface octahedral sites of $\gamma-\mathrm{Al}_{2} \mathrm{O}_{3}$ are reducible while cobalt ions occupying tetrahedral sites are not reducible at least at temperatures $\leq 900{ }^{\circ} \mathrm{C}$ [13]. Such preparation methods demand optimization of the metal dispersion on the catalyst and the degree of reduction $[14,15]$. It is known that $\mathrm{Co}^{+3}$ of $\mathrm{Co}_{3} \mathrm{O}_{4}$ can be gradually replaced by $\mathrm{Al}^{+3}$ to produce the series of $\mathrm{Co}_{3-\mathrm{s}} \mathrm{Al}_{\mathrm{s}} \mathrm{O}_{4}(0<\mathrm{s}<2)$ spinels. These series include $\mathrm{CoAl}_{2} \mathrm{O}_{4}, \mathrm{Co}_{2} \mathrm{AlO}_{4}, \mathrm{Co}_{3} \mathrm{O}_{4}$, and more. The interaction between $\mathrm{Co}_{3} \mathrm{O}_{4}$ and alumina could result in partial substitution of $\mathrm{Co}^{+3}$ ions in $\mathrm{Co}_{3} \mathrm{O}_{4}$ spinel by $\mathrm{Al}^{+3}$ ions, thereby hindering the reduction of cobalt species. Cobalt reducibility is known to depend on particle size [16]. The interaction of cobalt species with alumina should also be considered [17]. Alternatively, gas phase methods for cobalt-based catalyst preparation have been explored [18, 19].

Gas phase approaches such as the so-called liquid-feed flame spray pyrolysis (LF-FSP) method have been previously used to prepare $\mathrm{CoO}_{\mathrm{x}}-\mathrm{Al}_{2} \mathrm{O}_{3}$ particles [12]. In a FSP system, a metallorganic precursor dissolved in fuel (solvent) is aerosolized into droplets and ignited with a premixed methane-oxygen flame, the organic fuel combusts forming carbon dioxide and water vapor. The metallorganic component forms metal oxide particles. The entire process takes place in a time range of the order of miliseconds. Particles of varying morphologies (solid, hollow, porous, etc.) and sizes can be produced by controlling process parameters [20 - 22]. Particularly, the flame temperature, the residence time in the flame, and the droplet evaporation time play a key role in the particle formation. In a typical FSP, 
the droplets may undergo complete evaporation. In such case, the metallorganic precursor's vapor reacts and transforms into metal oxide vapor, which then forms small nanoparticles by homogeneous nucleation [20 - 22]. Nanoparticles synthesized via FSP exhibit typically small crystalline sizes and high surface areas. Particularly, in the synthesis of metal catalysts, aerosol methods ensure uniform dispersion of the active metal on a support material, unlike conventional wet-based methods. If the size of the metal nanoparticles is sufficiently small, the fraction of its surface atoms increases, thus improving catalyst performance.

In this work, Co-Al spinel nanoparticles were readily synthesized by a one-step FSP method. The approach allows the production of oxide nanoparticles at a relatively high rate. FSP provides an extremely short residence time of flame particles formation typically in the range of miliseconds $[23$, 24]. The particles were subsequently reduced to obtain metallic cobalt species and investigated in the conversion of glycerol in gas phase. Although, the reducibility of cobalt oxides is greatly decreased due to interaction with aluminium species, this strong interaction may prevent the aggregation of Co particles under the harsh reduction conditions. Reduction of cobalt species is determinant for its catalytic performance in the conversion of glycerol.

\section{Experimental}

\subsection{Catalyst preparation}

\subsubsection{Flame Spray Pyrolysis}

Aluminium acetylacetonate (99\%, Sigma-Aldrich) and cobalt acetate (99,995\%, Sigma-Aldrich) were used as received. The precursor solution consisted of a mixture of aluminium acetylacetonate $(0.078$ mol/l) and cobalt acetate $(0.017 \mathrm{~mol} / \mathrm{l})$ dissolved in a solution containing $73 \%$-v of methanol (J.T. Baker) in ion-exchanged water. The Co:Al ratio in the precursor solution was approximately 0.22 . 
The flame spray pyrolysis system used for particle preparation has been described previously [25] and is shown in Figure 1. Briefly, the precursor solution was fed through a capillary at a rate of $5 \mathrm{~mL} / \mathrm{min}$ and atomized with a high-pressure dispersion gas, $\mathrm{O}_{2}$, at a flow rate of $5 \mathrm{~L} / \mathrm{min}$. A premixed methaneoxygen flamelet with gas flow rates of 1 and $2 \mathrm{~L} / \mathrm{min}$, respectively, ignited the atomized precursor solution, resulting in the formation of a high-temperature flame, with temperatures in excess of $2000 \mathrm{~K}$. The produced particles were collected on a Teflon filter (Zefluor, Pall Corporation). Finally, the resultant cobalt sample obtained by flame spry pyrolysis was submitted to reduction treatment. Two reduction temperature treatments were investigated: $723 \mathrm{~K}$ and $1123 \mathrm{~K}$. The sample was reduced in a flow of $5 \% \mathrm{H}_{2} /$ Ar gas flowing at $20 \mathrm{~mL} / \mathrm{min}$ for 4 hours.

\subsection{Catalyst Characterization}

The morphology and structure of the particles were characterized with a transmission electron microscope (TEM, JEM-2100F, JEOL Ltd.) equipped with a field emission electron source and operated at $200 \mathrm{kV}$. For the analyses, samples were dispersed in an alcohol and a drop of the suspension was placed over a TEM grid with holey-carbon film. Surface structure and elemental composition of the particles were analyzed with a scanning electron microscope (SEM, JEOL JSM-35 C) and an energy dispersive X-ray spectroscope (EDS).

The surface characterization was carried out with X-ray photoelectron spectroscopy (XPS) on a SPECS system equipped with an $\mathrm{Al}$ anode XR50 source operating at $150 \mathrm{~mW}$ and a Phoibos $150 \mathrm{MCD}-9$ detector. The pressure in the analysis chamber was always below $10^{-7} \mathrm{~Pa}$. The area analyzed was approximately $2 \mathrm{~mm} \times 2 \mathrm{~mm}$. The pass energy of the hemispherical analyzer was set at $25 \mathrm{eV}$ and the energy step was set at $0.1 \mathrm{eV}$. Data processing was performed with the Casa XPS program (Casa Software Ltd., UK). Binding energy (BE) values were centered using the $\mathrm{C} 1 \mathrm{~s}$ peak at $284.8 \mathrm{eV}$. The atomic fractions (\%) were calculated using peak areas normalized based on acquisition parameters after 
background subtraction, experimental sensitivity factors and transmission factors provided by the manufacturer. The X-ray diffraction (XRD) analysis of the cobalt samples was recorded using a Siemens D5000 diffractometer (Bragg-Brentano for focusing geometry and vertical $\theta-\theta$ goniometer) with an angular 20-diffraction range between $5^{\circ}$ and $70^{\circ}$. The sample was dispersed on a $\mathrm{Si}(510)$ sample holder and spectra were collected with an angular step of $0.03^{\circ}$ at 9 s per step of sample rotation. $\mathrm{Cu} \mathrm{K \alpha}$ radiation $(\lambda=1.54056 \AA)$ was obtained from a copper $\mathrm{X}$-ray tube operated at $40 \mathrm{kV}$ and $30 \mathrm{~mA}$. The specific surface areas, cumulative pore volumes, and average pore diameters of the samples were measured by the Brunauer-Emmett-Teller (BET) method using $\mathrm{N}_{2}$ adsorption/desorption at $77 \mathrm{~K}$ in a Quantachrome Autosorb-1. Before measurement, each sample was degassed under vacuum at $473 \mathrm{~K}$ overnight. The BET specific surface area was calculated from the range $\mathrm{P} / \mathrm{P}_{0}=0.05-0.35$ in the adsorption branch while the pore size distribution was calculated from the desorption branch.

Temperature-programmed reduction (TPR) experiments were performed in a ThermoFinnigan (TPORD110) apparatus equipped with a thermal conductivity detector (TCD). The samples (pellets with size of $2-3 \mathrm{~mm}$ ) were then purged with an argon flow prior to the TPR. The analysis was carried out using a $5 \% \mathrm{H}_{2} / \mathrm{Ar}$ gas flowing at $20 \mathrm{~mL} / \mathrm{min}$ by heating from room temperature up to $1123 \mathrm{~K}$ with a heating rate of $10 \mathrm{~K} / \mathrm{min}$. The chemical composition of the samples was studied with a Thermo Nicolet 8700 FT-IR spectrometer using Attenuated Total Reflection (ATR) method.

\subsection{Catalytic Activity}

The catalytic conversion of glycerol was carried out in the gas phase in a quartz fixed-bed down flow reactor at $573 \mathrm{~K}$ for $6 \mathrm{~h}$. An aqueous solution of glycerol (3 v/v \%) was fed by a syringe pump with a flow of $3.5 \mathrm{~mL} / \mathrm{h}$ into the reactive gas. A hydrogen/glycerol molar ratio of 10 was used in all experiments. Typically, $100 \mathrm{mg}$ of sample in the form of pellets, sizes ranging $2-3 \mathrm{~mm}$, were loaded in the quartz reactor. 
The condensed products were trapped in an ice bath condenser and analyzed by HPLC every 20 minutes of reaction in a high-performance liquid chromatograph (HPLC, Agilent technologies 1100 series) equipped with a ICSep ICE-COREGEL 87H3 column (serial number 12525124), a diode-array detector (DAD), and a refractive index (RID) detector. The mobile phase was deionized and filtered with water at a controlled $\mathrm{pH}$ of 2.2 by addition of sulfuric acid with at a flow of $0.6 \mathrm{~mL} / \mathrm{min}$ and a pressure of 50 bar. The temperature of the HPLC column was $313 \mathrm{~K} .50$ minutes of analysis was used for each chromatogram.

The gaseous products were continuously analyzed by an on-line gas chromatograph equipped with a flame ionization detector (FID) and a HP Poraplot column $(30 \mathrm{~m} \times 0.53 \mathrm{~mm} \times 0.6 \mathrm{~m})$. Finally, a total organic carbon (TOC) analyzer was used to verify the carbon balance. The TOC analysis was performed on a Shimadzu TOC-5000A using high purity air (pressure of $400-500 \mathrm{kPa}$ and flow rate of $150 \mathrm{~mL} / \mathrm{min}$ ) and a furnace temperature of $953 \mathrm{~K}$. The conversion of the glycerol was defined as follows:

Conversion of glycerol $(\%)=\frac{\text { Mol of glycerol reacted }}{\text { Initial mol of glycerol }} \times 100$

The selectivity to each product was defined as selectivity based on carbon, where:

Selectivity $(\%)=\frac{\text { Mol of carbon in specific product }}{\text { Mol of carbon in all products }} \times 100$ 


\section{Results and Discussion}

\subsection{Properties and structure of as-synthesized particles}

The $\mathrm{N}_{2}$-physisorption results of the as-synthesized Co-Al spinel nanoparticles and Co-Al nanoparticles reduced at $1123 \mathrm{~K}$ are show in Table 1 . The as-synthesized Co-Al spinel nanoparticles present a surface area of $174 \mathrm{~m}^{2} / \mathrm{g}$ and pore volume of $1.21 \mathrm{~cm}^{3} / \mathrm{g}$. The nitrogen isotherm of the as-synthesized Co-Al nanoparticles and pore size distribution are shown in the Supporting Information (Figure S1a and $1 \mathrm{~b})$. The Co-Al nanoparticles reduced at $1123 \mathrm{~K}$ presents a surface area of $112 \mathrm{~m}^{2} / \mathrm{g}$ and pore volume of $0.68 \mathrm{~cm}^{3} / \mathrm{g}$. The reduction at $1123 \mathrm{~K}$ produced a decrease in the surface area and pore volume of the Co-Al spinel nanoparticles, suggesting that the reduction of cobalt spinel promotes formation of metallic cobalt species and partial agglomeration of the spinel material.

Figure 2 shows HRTEM images of the as-synthesized particles. Visual inspection of the images reveals that the size of the as-synthesized material is bimodal, containing abundant spherical particles with sizes ranging from $50 \mathrm{~nm}$ to $200 \mathrm{~nm}$ and much smaller particles with sizes between $3 \mathrm{~nm}-6 \mathrm{~nm}$. Figure $2 \mathrm{a}$ shows a low-magnification image of one large, spherical particle. Figures $2 \mathrm{~b}$ and $2 \mathrm{c}$ correspond to HRTEM images of the spherical particles together with the nanoparticles. The analyses also indicate that all the particles are crystalline. The lattice fringes measured in the particle depicted in the Figure $2 \mathrm{~b}$ at $2.86 \AA$ correspond to the (220) crystallographic planes of $\mathrm{Co}_{2} \mathrm{AlO}_{4}$; and several crystallographic domains are present. We refer to the lattice fringes visible inside the particle shown in the image, as indicated in the Figure $2 \mathrm{~b}$. The lattice fringes at 4.67 and $2.86 \AA$ in the Fourier Transform (FT) image of the spherical particle in Figure 2c correspond to the (111) and (220) crystallographic planes of $\mathrm{Co}_{2} \mathrm{AlO}_{4}$, respectively. In this particular case, the spherical particle is a single crystal. Figure 2d shows another HRTEM image of a spherical particle with its corresponding FT image. The spots at 
$2.44 \AA$ belong to the (311) crystallographic planes of $\mathrm{Co}_{2} \mathrm{AlO}_{4}$. A HRTEM image of a nanoparticle next to a large, spherical particle is shown in Figure 2e. In both cases, the lattice fringes at $2.86 \AA$ correspond to the (220) crystallographic planes of $\mathrm{Co}_{2} \mathrm{AlO}_{4}$. The analyses thus show that both the large, spherical particles and the nanoparticles have the same composition. Note that the crystallographic parameters of $\mathrm{Co}_{2} \mathrm{AlO}_{4}, \mathrm{CoAl}_{2} \mathrm{O}_{4}$, and $\mathrm{Co}_{3} \mathrm{O}_{4}$ are nearly the same, so it is rather difficult to distinguish them by HRTEM or XRD. The observed bimodality in the size distribution of the Co-aluminate particles likely arises from an incomplete combustion of the atomized precursor droplets [20].

In the typical flame spray synthesis when the metallorganic precursors decompose, the organic part undergoes complete combustion to carbon dioxide and water vapor while the metallic components form metal oxide nanoparticles by homogeneous nucleation $[20,26]$. However, it is known the addition of water to the precursor solution decreases the flame temperature [27]. Such a drop leads to an incomplete burning of droplets resulting in formation of large metal oxide particles and organics. Nevertheless, the fraction of precursor evaporated from the droplets undergoes homogeneous nucleation thus producing metal oxide nanoparticles. The presence of traces of organic compounds in FTIR analyses (Figure 3) suggest the occurrence of incomplete combustion. FTIR spectra of assynthesized $\mathrm{Co} / \mathrm{Al} / \mathrm{O}$ spinel and $\mathrm{Al}_{2} \mathrm{O}_{3}$ powder produced with $\mathrm{FSP}$ are presented in Figure 3 . The band observed around $3400 \mathrm{~cm}^{-1}$ is assigned to the $-\mathrm{OH}$ stretching mode due to the surface absorbed water [28]. The bands in the $1600-1400 \mathrm{~cm}^{-1}$ region are most likely due to traces of organic species (e.g. $\mathrm{COO}^{-}$) on the particle surface. The peak observed around $1345 \mathrm{~cm}^{-1}$ is assigned to asymmetric vibration of carbonate [28]. The bands between $555-1020 \mathrm{~cm}^{-1}$ may be related to the spinel structure of the powder [29 - 31]. In addition, the shoulder observed at $798 \mathrm{~cm}^{-1}$ in the spectra of $\mathrm{Co} / \mathrm{Al} / \mathrm{O}$ spinel is likely due to $\mathrm{Co}^{2+}$ ions occupying mainly octahedral sites of the spinel [32]. 
Figure 4 shows SEM images and its corresponding EDS analysis of the particles (Table 2). The green dots indicate that Co is uniformly distributed in the alumina matrix. The XRD patterns of the assynthesized nanoparticles in Figure 5 reveal the presence of the cobalt aluminum oxide phase $\left(\mathrm{Co}_{2} \mathrm{AlO}_{4}\right)$-FD-3m-(227). However, $\mathrm{Co}_{2} \mathrm{AlO}_{4}, \mathrm{CoAl}_{2} \mathrm{O}_{4}$ and $\mathrm{Co}_{3} \mathrm{O}_{4}$ have similar peak positions in the diffraction pattern, thus making difficult the identification of Co-containing phases with XRD [33 - 35]. Based on the phase diagram of the $\mathrm{CoO}-\mathrm{Al}_{2} \mathrm{O}_{3}$ systems the formation of off-stoichiometric spinel, i.e. $22 \mathrm{~mol} \%$ of Co together with $\mathrm{Al}_{2} \mathrm{O}_{3}$, is expected [12]. Such value correlates well with the weight percentages obtained from EDS analyses (see Table 2). It must be added that there is no evaporation of cobalt species as a consequence of the reduction process at $1123 \mathrm{~K}$, since the elemental composition (EDS, see SI Figure S2 and Table S1) of the reduced Co-Al spinel nanoparticles revealed a Co/Al atomic ratio near to 0.25 . This value is in close agreement with the $\mathrm{Co} / \mathrm{Al}$ atomic ratio of 0.25 observed for the as-synthesized Co-Al spinel nanoparticles (Table 2).

XPS of fresh sample has a clean surface with only bands due to $\mathrm{Co}, \mathrm{Al}$ and $\mathrm{O}$ as well as adventitious $\mathrm{C}$. The surface atomic ratio $\mathrm{Co} / \mathrm{Al}$ is 0.27 , which is lower than that of nominal $\mathrm{CoAl}_{2} \mathrm{O}_{4}(0.5)$, meaning that the surface is enriched relatively in Al (Table 3 ). The analysis of the Co $2 p$ photoelectrons is shown in Table 3. The band is rather complex and contain core level photoelectrons as well as satellite lines. The relative intensity of the satellite lines and the binding energy of the core level photoelectrons correspond well to $\mathrm{CoAl}_{2} \mathrm{O}_{4}$.

\subsection{Reduction of the as-synthesized material}

The XRD pattern of the as-synthesized Co-Al spinel nanoparticle is presented in Figure 5 and revealed the presence of cobalt aluminum oxide species $\left(\mathrm{Co}_{2} \mathrm{AlO}_{4}, \mathrm{Fd}-3 \mathrm{~m}-(227)\right)$. The cobalt sample reduced in hydrogen at $723 \mathrm{~K}$ presents also $\mathrm{Co}_{2} \mathrm{AlO}_{4}$ species (Figure 5). However, when the sample was reduced 
at $1123 \mathrm{~K}$ part of the cobalt oxide species get reduced to face centered cubic structure (fcc) cobalt (FD$3 \mathrm{~m}-(225))[36,37]$ as indicated in Figure 5. We also identified $\gamma-\mathrm{Al}_{2} \mathrm{O}_{3}$ phase in the as-synthesized CoAl nanoparticles. Thus, catalyst reduction at $1123 \mathrm{~K}$ produces a metallic cobalt containing phase.

The reduced sample has two fundamental differences with respect to the as-synthesized catalyst. These are: (i) the appearance of nanoparticles of about 3-8 $\mathrm{nm}$ in size with higher electron contrast than $\mathrm{Co}_{2} \mathrm{AlO}_{4}$, and (ii) the appearance of agglomerates of shells that resemble empty spherical particles. Figure 6a shows a low-magnification HRTEM view where, in addition to the spherical particles and nanoparticles found in the as-synthesized material, a dispersion of nanoparticles with a markedly high electron contrast is observed. Figure $6 \mathrm{~b}$ shows a complex structure consisting of an agglomerate of shells. An HRTEM image of a shell is shown in Figure 6c. Contrarily to the existence of large crystalline domains that are observed in the as-synthesized sample, in the reduced catalyst the shells are constituted by numerous nanocrystals randomly oriented. This is clearly seen in the electron diffraction pattern shown in Figure 6c, where the existence of diffraction rings is a direct consequence of the presence of numerous crystallites with random orientation. The crystallographic spacing recorded at 4.7 $\AA, 2.8 \AA, 2.4 \AA$ and $2.0 \AA$ correspond to the $\mathrm{Co}_{2} \mathrm{AlO}_{4}$ structure. The nanoparticles with high electron contrast correspond to metallic Co as deduced from the HRTEM analysis. Figure $6 \mathrm{~d}$ shows a Co nanoparticle along with its FT image. Spots at $2.02 \AA$ and $1.91 \AA$ correspond to the $(002)$ and (101) planes of the hexagonal structure of metallic cobalt, respectively. In addition, the lattice fringes at 2.46 $\AA$ recorded at the periphery of the Co nanoparticle is ascribed to the (111) crystallographic planes of $\mathrm{CoO}$, which may constitute an intermediate of the reduction process of $\mathrm{Co}_{2} \mathrm{AlO}_{4}$ into metallic Co. The Co metal nanoparticles are encountered both in the hexagonal and cubic structures. Figure 7a shows a cubic Co nanoparticle of $2 \mathrm{~nm}-3 \mathrm{~nm}$ in size; spots at $2.05 \AA$ and $1.77 \AA$ correspond to the (111) and 
(200) crystallographic planes of cubic Co, respectively. Another example is shown in Figure 7b, where lattice fringes of both $\mathrm{Co}_{2} \mathrm{AlO}_{4}$ at $2.86 \AA$ and cubic $\mathrm{Co}$ at $2.05 \AA$ are identified.

TPR of the as-synthesized Co-Al spinel nanoparticles was performed to follow the transformation of the cobalt species in the aluminate material towards active metal cobalt for catalyzing the glycerol conversion. As stated before, the TPR analysis was carried out using a 5\% $\mathrm{H}_{2} / \mathrm{Ar}$ gas flowing at 20 $\mathrm{mL} / \mathrm{min}$ by heating from room temperature up to $1123 \mathrm{~K}$ with a heating rate of $10 \mathrm{~K} / \mathrm{min}$. The TPR profile of the catalyst powders showed two major fingerprints (Figure 8). The TPR peak between 493 $\mathrm{K}$ and $763 \mathrm{~K}$ is related to $\mathrm{Co}_{3} \mathrm{O}_{4}$ species. The reduction of $\mathrm{Co}_{3} \mathrm{O}_{4}$ species usually exhibits only one TPR peak [38]. The broad peak between $493 \mathrm{~K}$ and $763 \mathrm{~K}$ is an indicative of a two-stage reduction of $\mathrm{Co}_{3} \mathrm{O}_{4}$ to $\mathrm{Co}$ via $\mathrm{CoO}$ species $\left(\mathrm{Co}_{3} \mathrm{O}_{4} \rightarrow \mathrm{CoO} \rightarrow \mathrm{Co}\right)$. The peaks between $773 \mathrm{~K}$ and $1193 \mathrm{~K}$ can be assigned to the reduction of cobalt oxides species $\left(\mathrm{Co}^{2+}\right.$ and $\left.\mathrm{Co}^{3+}\right)$ which strongly interact with the aluminate $\left(\mathrm{Co}_{\mathrm{x}} \mathrm{O}_{\mathrm{y}} / \mathrm{Al}_{2} \mathrm{O}_{3} \rightarrow \mathrm{Co}^{\circ}\right)$ [38]. It can be suggested that the lower broad temperature peak may be due to easily reduced bulk oxide [39], whereas the high temperature peak may be due to the presence of the strong interactions of the cobalt oxide species with aluminium species [40]. It should be noted that the high temperature peak exhibited an asymmetric form suggesting the presence of at least two distinct high temperature reduction peaks. It must be added, as reported by previous work [40], that the temperature range higher than $1000 \mathrm{~K}$ (Figure 8) is attributed to the reduction of $\mathrm{CoAl}_{2} \mathrm{O}_{4}$.

The reduced sample $(1123 \mathrm{~K})$ has a different surface composition from of the as-synthesized material as shown by the XPS results on Table 3 . The $\mathrm{Co} / \mathrm{Al}$ atomic ratio has decreased to $\mathrm{Co} / \mathrm{Al}=0.11$, which represents a significant reduction in the exposed cobalt (Table 4). This is in accordance with the reduction of $\mathrm{CoAl}_{2} \mathrm{O}_{4}$ into metallic $\mathrm{Co}$ and partial agglomeration (sintering) of Co. However, the high resolution Co $2 \mathrm{p}$ spectrum does not show any feature of metallic Co (Figure 9). Considering that 
HRTEM evidenced the existence of metallic Co, the absence of such feature in the XPS is interpreted as re-oxidation of the surface. Accordingly, the spectrum (Figure 9) has a different proportion of bands and, in particular, the satellite lines have decreased their intensity strongly, which implies that the structure of $\mathrm{CoAl}_{2} \mathrm{O}_{4}$ has transformed into a new metallic Co-containing phase.

\subsection{Catalytic activity}

The conversion of glycerol at $573 \mathrm{~K}$ under atmospheric pressure and in the presence of hydrogen was used to investigate the performance of the $\mathrm{Co}-\mathrm{Al}$ reduced at $1123 \mathrm{~K}$. The as-synthesized Co-Al spinel nanoparticle was not active in the glycerol conversion. The reduction step $1123 \mathrm{~K}$ of the Co-Al spinel nanoparticles was determinant to form metallic cobalt species and modulate the catalytic activity.

The major products in the condensable phase were: compounds with three carbon atoms (dehydration and dehydrogenation products) such as hydroxyacetone, pyruvaldehyde, lactide and lactic acid. The major product detected in the gas phase was methane $\left(\mathrm{CH}_{4}\right)$, originated from the $\mathrm{C}-\mathrm{C}$ bond cleavage by hydrogenolysis, and traces of acetone.

Figure $10 \mathrm{a}$ and $10 \mathrm{~b}$ shows the catalytic activity of Co-based catalyst as a function of time. The catalytic test with the reduced $\mathrm{Co}-\mathrm{Al}$ spinel nanoparticles at $1123 \mathrm{~K}$ preferentially promotes dehydration and dehydrogenation of glycerol, yielding hydroxyacetone, pyruvaldehyde, pyruvic acid, lactid acid and methane as main products. The selectivity to $\mathrm{CH}_{4}$ increased from $10 \%$ (20 minutes of reaction) to 20 $\%$ after $4 \mathrm{~h}$ of reaction. The selectivity of lactic acid is initially at about $30 \%$ and then decreases progressively to approximately $5 \%$ after $4 \mathrm{~h}$ of reaction. The decrease in lactic acid selectivity is accompanied by an increase of lactide. Hydroxyacetone selectivity decreased from $30 \%$ to $20 \%$ with 
raising time of reaction. Acetone selectivity is the lowest, rising to approximately $4 \%$ with reaction time.

One possible production route for lactic acid is through a cascade reaction whereby firstly glycerol is dehydrated to hydroxyacetone. Hydroxyacetone is thus dehydrogenated to pyruvic aldehyde on the metal catalyst and the aldehyde is then converted to lactic acid through intramolecular disproportionation (Cannizzaro reaction). Lactide is a cyclic dimer obtained from the lactic acid. This route is indeed in close agreement with previous results reported in the literature [41].

The conversion of glycerol at $3 \mathrm{~h}$ of reaction (Table 5) was about $19.1 \%$ of hydroxyacetone, $23.2 \%$ of pyruvaldehyde, $8.4 \%$ of lactic acid, $27.1 \%$ of lactide; $3.2 \%$ of acetone and $19 \%$ of $\mathrm{CH}_{4}$. The carbon balance is in close agreement with previous work reported in the literature $[42,43]$. This fact reinforces the observed deactivation of the catalyst during the glycerol conversion over the Co-Al spinel nanoparticles.

Based on our previous work [43] a large portion of the product was pyruyvaldehyde, lactic acid, lactide and methane when the reactant was hydroxyacetone instead of glycerol. Methane can be obtained from the catalytic $\mathrm{C}-\mathrm{C}$ bond cleavage of the hydroxyacetone. Therefore, we consider that the production route of lactic acid from hydroxyacetone may also be occurring in our systems. Traces of acetone was also observed which probably comes from the hydrogenation of hydroxyacetone to 1,2 propanediol and acetone finally is formed from the dehydration of 1,2 propanediol. A plausible reaction route is shown in Figure 10c. The effect of bifunctional metal-acid properties of the catalysts can be visualized in two main routes: (i) hydrogenolysis of glycerol to methane and (ii) dehydration-dehydrogenation to the production of hydroxyacetone, pyruvaldehyde and lactic acid and acetone. 
A decrease in the glycerol conversion from $80 \%$ at the beginning to $\sim 35 \%$ after $4 \mathrm{~h}$ of reaction suggests catalyst deactivation (see Figure 10). The formation of carbon deposits during the dehydration of glycerol presumably contributes to catalyst deactivation. The carbon deposits may result from side reactions between dehydrated products of glycerol such as deep conversion of hydroxyacetone to produce methane [44]. The formation of carbonaceous deposits, known as cooking of the catalyst, is an undesired side reaction, on which, especially the reaction temperature and the kind of reactant feed, have a great influence. Coke deposition appears to be correlated with the total acidity of a catalyst [45]. Catalyst characterization by adsorption of carbon monoxide using FTIR has been addressed in many publications to study the nature of surface sites in cobalt catalysts. Carbon monoxide species adsorbed on $\mathrm{Co}^{+2}$ and $\mathrm{CO}^{+3}$ on Lewis acid sites were detected in previous studies [46, 47] and coke deposits are formed on the acid sites of the catalyst leading to the deactivation. It must be added also that the reduction at $1123 \mathrm{~K}$ of $\mathrm{Co}-\mathrm{Al}$ spinel nanoparticles to produce metallic cobalt species is determinant for glycerol conversion.

The acid properties of the samples as measured by TPD- $\mathrm{NH}_{3}$ are presented in Figure 11. The TPD profile is a broad peak where most of the $\mathrm{NH}_{3}$ desorption occurred below $773 \mathrm{~K}$. The amount of $\mathrm{NH}_{3}$ desorbed per gram of catalyst is $0.6 \mathrm{mmol} / \mathrm{g}$ and the acid sites density is $5.8 \mu \mathrm{mol} / \mathrm{m}^{2}$ (see Table 6 ). In general, spinel-type mixed oxides are materials that it is not expected to possess surface hydroxyl groups especially in the reduction conditions $\left(1123 \mathrm{~K}_{\text {in }} \mathrm{H}_{2}\right)$ used in the catalyst preparation protocol. Thus, the measured surface acidity in this material should be of the Lewis type. 
Previous work Atia et al. [48] observed catalyst deactivation during dehydration of glycerol on heteropolyacid catalysts attributed to the blocking of the catalyst surface by carbon, which was related to the catalyst acidity. Catalyst deactivation observed during the catalytic conversion of glycerol is due to deposition of carbon species on the surface of the catalyst decreasing greatly the availability of the required active centers and consequently depressing the overall activity as reported in our previous work [43]. Regeneration of catalysts deactivated by carbon deposition is typically carried out in industrial process by removing the coke formed on the catalyst surface with oxidation of the coke with oxygen or air [49]

It must be added that very recently, Sato et al. reported that the vapour phase glycerol dehydration to hydroxyacetone over Ag supported catalysts showed glycerol conversion of $91 \%$ with $86 \%$ selectivity to hydroxyacetone at $513 \mathrm{~K}$ in $\mathrm{H}_{2}$ flow [50]. Chiu et al. [51] reported gas-phase conversion of glycerol to hydroxyacetone in a semi-batch reactor at high pressure and temperature by reactive distillation over copper chromite catalyst with $22 \%$ conversion of glycerol and $70 \%$ selectivity to hydroxyacetone [51]. However, toxicity associated with $\mathrm{Cr}$ species in these catalysts necessitates the development of a new generation of catalysts. The present work exhibits an alternative catalytic system based on non-noble metals such as cobalt able to transform glycerol to lactic acid in one pot via hydroxyacetone as intermediate. One the most important cascade reactions in conversion of bio-based feedstock, is the conversion of glycerol to green bulk chemicals in one pot such as lactic acid (LA). The market demand of lactic acid grows rapidly because it can be used as the monomer for the synthesis of biodegradable poly (lactic acid) (PLA). PLA is biocompatible which motivates its use in medicine for controllable release of drugs in the blood stream and orthopedic implants. 


\section{Conclusions}

Cobalt aluminate nanoparticles were prepared by flame spray pyrolysis. Co-Al spinel nanoparticles reduced at $1123 \mathrm{~K}$ were found to be catalytically active in the conversion of glycerol in gas phase. The reduction process of $\mathrm{Co}-\mathrm{Al}$ spinel nanoparticles promoted the formation of a new metallic Cocontaining phase. The presence of metallic cobalt species is crucial for the glycerol conversion. XPS analysis revealed that the $\mathrm{Co} / \mathrm{Al}$ atomic ratio has decreased to $\mathrm{Co} / \mathrm{Al}=0.11$ as the reduction temperature increased indicating an increase of the exposed metallic cobalt species. HRTEM also reinforced the formation of metallic cobalt species after Co-Al spinel nanoparticles reduction at $1123 \mathrm{~K}$. The main products obtained from the conversion of glycerol using the reduced Co-Al spinel based nanoparticles was hydroxyacetone, pyruvaldehyde, actic acid and lactide. Flame spray pyrolysis successfully gave insights to ensure uniform dispersion of the active metal on a support material.

\section{Acknowledgements}

R. J. Chimentão acknowledges the Ministry of Science and Technology for the financial support for the Juan de la Cierva program (JCI-2010-07328) and Vicerrectoria de Investigación y Desarrollo, Universidad de Concepción for the financial support (VRID 217.022.027-1.0 IN). LBML acknowledges financial support from the Ministry of Economy and Competitiveness of Spain through a 'Juan de la Cierva' Research Fellowship. 


\section{References}

[1] M. D. Serio, R. Tesser, L. Pengmei, E. Santacesaria. Heterogeneous catalysts for biodiesel production. Energy Fuels, 22 (2008) 207-217.

[2] C.H. Zhou, J. N. Beltramini, Y. X.Fan, G.Q. Lu. Chemoselective catalytic conversion of glycerol as a biorenewable source to valuable commodity chemicals. Chem. Soc. Rev. 37 (2008) 527-549.

[3] REN21. 2016. Renewables 2016 Global Status Report (Paris: REN21 Secretariat). ISBN 978-39818107-0-7.

[4] R.D. Cortright, M. Sanchez-Castillo, J. A. Dumesic, Conversion of biomass to 1,2 propanediol by selective catalytic hydrogenation of lactic acid over silica-supported copper. Appl. Catal. B 39 (2002) $353-359$.

[5] L. Guo, J. Zhou, J. Mao, X. Guo, S. Zhang. Supported Cu catalysts for the selective hydrogenolysis of glycerol to propanediols. Appl. Catal. A, 367(1-2) (2009) 93-98.

[6] F. Auneau, C. Michel, F. Delbecq, C. Pinel, P. Sautet, Unrevelling the mechanism of glycerol hydrogenolysis over rhodium catalyst through combined experimental theoretical investigations, Chem. Eur. J., 17 (2011) 14288-14299. 
[7] F. G. Gault, Advances in Catalysis and related subjects, vol 30, p.1, Academic Press, New York/London 1981.

[8] J.H. Sinfelt, Bifunctional Catalysis. Advances in Chemical Engineering, 5 (1964) 37-74.

[9] H.A. Gasteiger, N.M. Markovic, Just a Dream - or Future reality. Science, 324 (2009) 48.

[10] F. Chen, C. Topf, J. Radnik, C. Kreyenschulte, H. Lund, M. Schneider, A.-E. Surkus, L. He, K. Junge, M. Beller. Stable and inert cobalt catalysts for highly selective and practical hydrogenation of CN and C-O bonds. J. Am. Chem. Soc., 138 (2016) 8781-8788.

[11] F. Dumond, E. Marceau, M. Che. A study of cobalt speciation in $\mathrm{Co} / \mathrm{Al}_{2} \mathrm{O}_{3}$ catalysts prepared from solutions of cobalt-ethylenediamine complexes. J. Phys. Chem. C, 111 (2007) 4780-4789.

[12] J. A. Azurdia, J. MArchal, P. Shea, H. Sun, X. Q. Pan, R. M. Laine. Liquid-feed flame spray pyrolysis as a method of producing mixed-metal oxide nanopowders of potential interest as catalytic materials. Nanopowders along the $\mathrm{NiO}-\mathrm{Al}_{2} \mathrm{O}_{3}$ tie line including $(\mathrm{NiO})_{0.22}\left(\mathrm{Al}_{2} \mathrm{O}_{3}\right)_{0.78}$, a new inverse spinel composition. Chem. Mater., 18 (2006) 731-739.

[13] R.L.Chin, D.M. Hercules, Surface spectroscopic characterization of cobalt-molybdenum-alumina catalysts. J. Phys. Chem. A, 86 (1982) 360 - 367. 
[14] N. Ouahdi, S. Guillemet, J.J. Demai, B. Durand, L. E. Rakho, R. Moussa, A. Samdi, Investigation of the reactivity of $\mathrm{AlCl}_{3}$ and $\mathrm{CoCl}_{2}$ toward molten alkali-metal nitrates in order to synthesize $\mathrm{CoAl}_{2} \mathrm{O}_{4}$. Mater. Lett., 59 (2005) 334-340.

[15] E. Iglesia, Design, synthesis and use of cobalt-based Fischer-Tropsch synthesis catalysts. Appl. Catal. A, 161 (1997) 59-78.

[16] A. Y. Khodakov, A. C. Constant, R. Bechara, F. Villain, Pore-size control of cobalt dispersion and reducibility in mesoporous silicas. J. Phys. Chem. B, 105 (2001) 9805-9811.

[17] A.A. Khassin, T.M. Yurieva, V.V. Kaichev, V.I. Bukhtiyarov, A.A. Budneva, E.A. Paukshtis,V.N. Parmon, Metal-support interactions in cobalt aluminum co-precipitated catalysts : XPS and CO adsorption studies. Journal of Molecular Catalysis A: Chemical, 175 (1-2) (2001) 189-204.

[18] R. Moene, M. Makkee, J.A. Moulijn, Novel application of catalysis in the synthesis of catalysts, Catalysis Letters 34 (1995) 285-291

[19] G. Che, B.B. Lakshmi, C.R. Martin, E.R. Fisher, Chemical vapour deposition based synthesis of carbon nanotubes and nanofibers using a template method, Chem. Mater. 10 (1998) 260-267.

[20] L. Mädler, H.K. Kammler, R. Mueller, S.E. Pratsinis, Controlled synthesis of nanostructured particles by flame spray pyrolysis. J. Aerosol Sci., 33 (2002) 369-389. 
[21] H.K. Kammler, L. Mädler, S.E. Pratsinis, Flame Synthesis of Nanoparticles. Chem. Eng. Technol., 24 (2001) 583-596.

[22] A.J. Gröhn, S.E. Pratsinis, K. Wegner. Fluid-particle dynamics during combustion spray aerosol synthesis of $\mathrm{ZrO}_{2}$. Chem. Eng. J., 191 (2012) 491-502.

[23] W. Y. Teoh, A perspective on the flame spray synthesis of photocatalyst nanoparticles, Materials 6 (2013) 3194-3212.

[24] H. Shirae, K.Hasegawa, H. Sugime, E. Yi, R. M. Laine, S. Noda, Catalyst Nucleation and Carbon Nanotube Growth from Flame-Synthesized Co-Al-O Nanopowders at Ten-Second Time Scale, Carbon, (2017) 114 31-38.

[25] T. Karhunen, A. Lähde, J. Leskinen, R. Büchel, O. Waser, U. Tapper, J. Jokiniemi. Transition metal-doped lithium titanium oxide nanoparticles made using flame spray pyrolysis. ISRN Nanotechnology, Article ID 180821, 2011, 6pp.

[26] M. Sokolowski, A. Sokolowska., A. Michalski, B. Gokieli. The "in-flame-reaction" method for $\mathrm{Al}_{2} \mathrm{O}_{3}$ aerosol formation. J. Aerosol Sci., 8 (1977) 219-230. 
[27] J. Gagan, G. Pelagia-Irene, Flame Spray Pyrolysis Processing to Produce Metastable Phases of Metal Oxides. JOJ Material Sci. 1(2) (2017) 555557.

[28] D. C. L. Vasconcelos, E. H. M. Nunes, W. L. Vasconcelos. AES and FTIR characterization of solgel alumina films. Journal of Non-crystalline Solids, 358 (2012) 1374-1379.

[29] X. Duan, M. Pan, F. Yu, D. Yuan. Synthesis, structure and optical properties of $\mathrm{CoAl}_{2} \mathrm{O}_{4}$ spinel nanocrystals. Journal of Alloys and Compounds, 509 (2011) 1079-1083.

[30] L. Ji, S. Tang, H. C. Zeng, J. Lin, K. L. Tan. $\mathrm{CO}_{2}$ reforming of methane to synthesis gas over solgel-made $\mathrm{Co} / \mathrm{g}-\mathrm{Al}_{2} \mathrm{O}_{3}$ catalysts from organometallic precursors. Appl. Catal. A, 2017 (2001) 247 - 255.

[31] L. Ji, J. Lin, H. C. Zeng. Metal - Support Interactions in $\mathrm{Co} / \mathrm{Al}_{2} \mathrm{O}_{3}$ Catalysts: A comparative study on reactivity of support. J. Phys. Chem. B, 104 (2000) $1783-1790$.

[32] N. M. Deraz, M. M. G. Fouda. Synthesis, structural, morphological properties of cobalt-Aluminum nano-composite. Int. J. Electrochem. Sci., 8 (2013) 2756-2767.

[33] B. Jongsomjit, J. G. Goodwin Jr. Co-support compound formation in $\mathrm{Co} / \mathrm{Al}_{2} \mathrm{O}_{3}$ catalysts: effect of reduction gas containing CO. Catalysis Today 77 (2002) 191-204. 
[34] S. Rojanapipatkul, J. G. Goodwin Jr., P. Praserthdam, B. Jongsomjit. Effect of cobalt precursors on properties of $\mathrm{Co} / \mathrm{CoAl}_{2} \mathrm{O}_{4}$ catalysts synthesized by solvothermal method. Engineering Journal, 16(4), 2012, 13 pp, DOI:10.4186/ej.2012.16.4.5

[35] W. Chu, P. A. Chernavskii, L. Gengembre, G. A. Pankina, P. Fongarland, A. Y. Khodakov, Cobalt species in promoted alumina-supported Fischer-Tropsch catalysts. Journal of Catalysis 252 (2007) 215230.

[36] O. Ducreux, J. Lynch, B. Rebours, M. Roy, P. Chaumette, Studies in surface science and catalysis 119 (1998) 125-130.

[37] B. Strauss, F. Frey, W. Petry, J. Trampenau, K. Nicolaus, S.M. Shapiro, J. Bossy, Martensitic phase transformation and lattice dynamics of fcc cobalt. Phys. Rev. B, 1996, 54, 6035.

[38] P. Arnoldy, J. A. Moulijn. Temperature-programmed reduction of $\mathrm{CoO} / \mathrm{Al}_{2} \mathrm{O}_{3}$ catalysts. Journal of Catalysis, 93, 1985, 38-54.

[39] A. Kogelbauer, J. Weber, J.G. Jr. Goodwin, The formation of cobalt silicates on $\mathrm{Co} / \mathrm{SiO} 2$ under hydrothermal conditions. Catalysis Letters 34, (1995) 259-267. 
[40] J. S. Jung, G. Hong, E.H. Yang, Y.S. Noh, D.J. Moon, Characterizations and kinetics studies for the Fischer Tropsch synthesis over $\mathrm{Co} / \mathrm{Al}_{2} \mathrm{O}_{3}$ catalyst. Journal of Nanoscience and Nanotechnology 16 (2016) 10397-10403.

[41] L. Kong, G. Li, H. Wang, W. He, F. Ling, Hydrothermal catalytic conversion of biomass for lactic acid production. J. Chem. Technol. Biotechnol. 83 (2008) 383-388.

[42] T. Jiang, Q. Huai, T. Geng, W. Ying, T. Xiao, F. Cao, Catalytic performance of Pd-Ni bimetallic catalyst for glycerol hydrogenolysis, Biomass and bioenergy 78 (2015) 71-79

[43] B. Miranda, R.J. Chimentão, J.B.O. Santos, F.G. Gispert-Guirado, J. Llorca, F. Medina, F. Lopez Bonillo, J. E. Sueiras, Conversion of glycerol over $10 \% \mathrm{Ni} / \gamma-\mathrm{Al}_{2} \mathrm{O}_{3}$ catalyst. Appl. Catal. B, 147 (2014) 464-480.

[44] A. Corma, P. J. Miguel, A. V. Orchillés. The role of reaction temperature and cracking catalyst characteristics in determining the relative rates of protolytic cracking, chain propagation, and hydrogen transfer. J. Catal., 145 (1994) 171-180.

[45] W. Suprun, M. Lutecki, T.Haber, H. Papp, Acid catalysis for the dehydration of glycerol: Activity and deactivation. Journal of Molecular Catalysis A. Chemical 309 (2009) 71-78. 
[46] A. Y.Khodakov, W. Chu, P. Fongarland, Advances in the development of novel cobalt FischerTropsch synthesis of long chain hydrocarbons and clean fuels. Chemical Rev. 107 (2007) 1692-1744.

[47] G. R. Fredriksen, E. A. Blekkan, D. Schanke, A. Holmen, CO hydrogenation over supported cobalt catalysts: FTIR and gravimetric studies. Chemical Engineering Technology 18 (1995) 125-131.

[48] H. Atia, U. Armbruster, A. Martin, Dehydration of glycerol in gas phase using heteropolyacid catalysts as active compounds, Journal of Catalysis 258 (2008) 71-82.

[49] K. J. Marschall and L. Mleczko, Short-contact-time reactor for catalytic partial oxidation of methane, Ind. Eng. Chem. Res. 38(5) 1999 1813-1221.

[50] S. Sato, D. Sakai, F. Sato, Y. Yamada, Vapor-phase dehydration of glycerol into hydroxyacetone on silver catalysts, Chemistry Letters 41 (2012) 965-966.

[51] C. W. Chiu, A. Tekeei, W. R. Sutterlin, J. M. Ronco, G. J. Suppes, Low-pressure packed-bed gas phase conversion of glycerol to acetol, AIChE J. 54 (2008) 2456. 


\section{Caption to Figures}

Figure 1. Schematics of the Flame Spray Pyrolysis system.

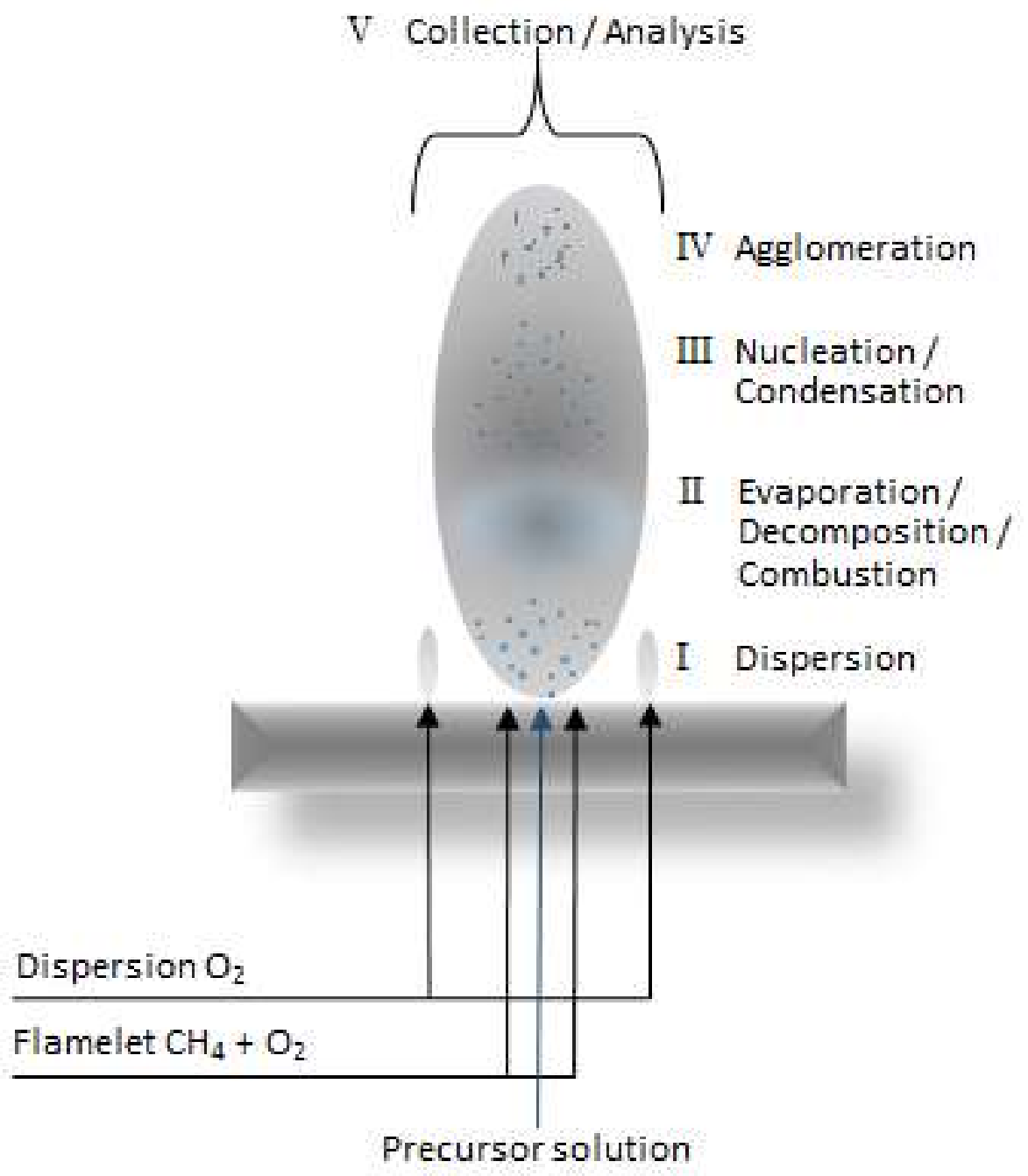



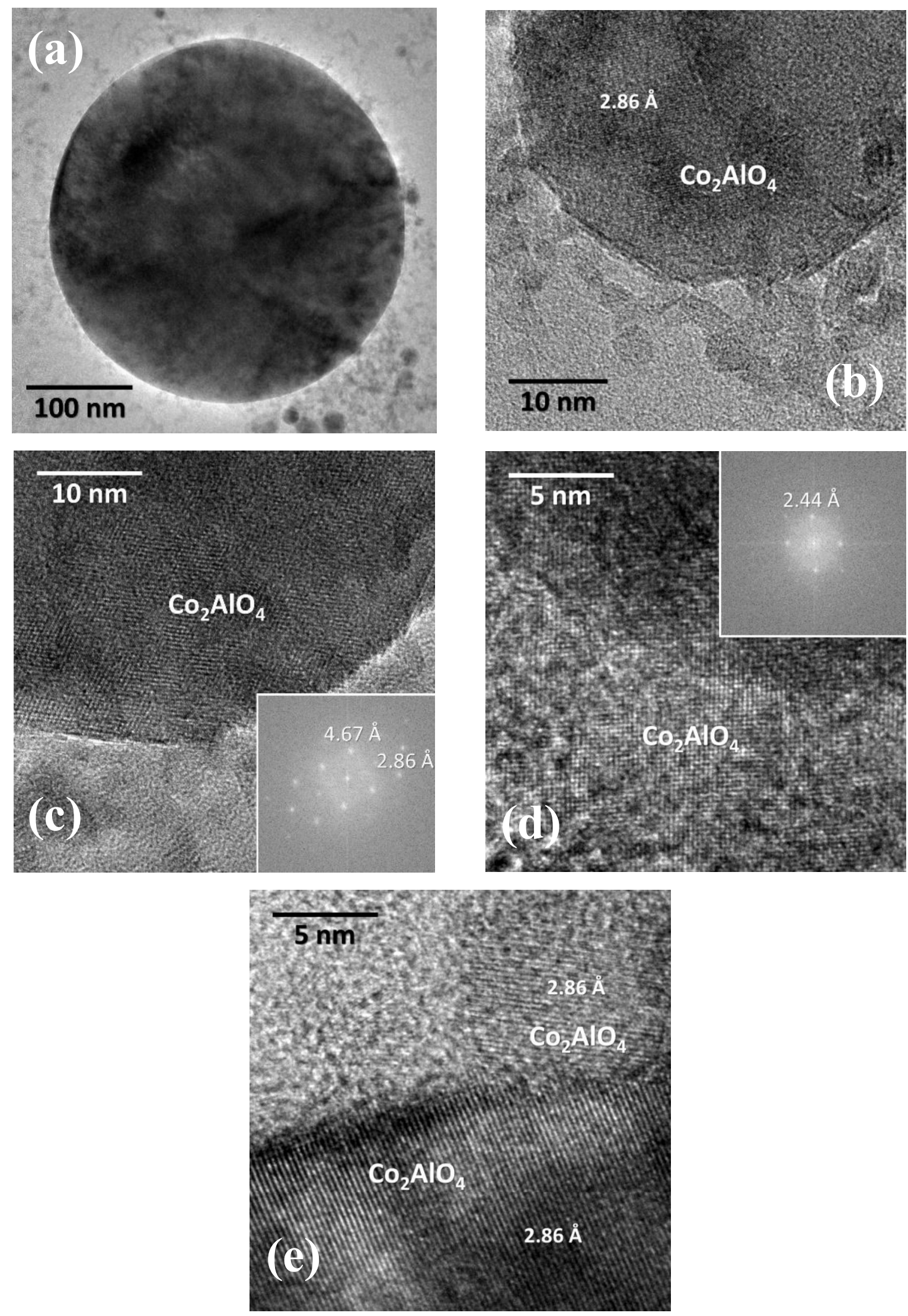

Figure 2. HRTEM images of the Co-Al spinel nanoparticles synthesized by fame spray pyrolisis 


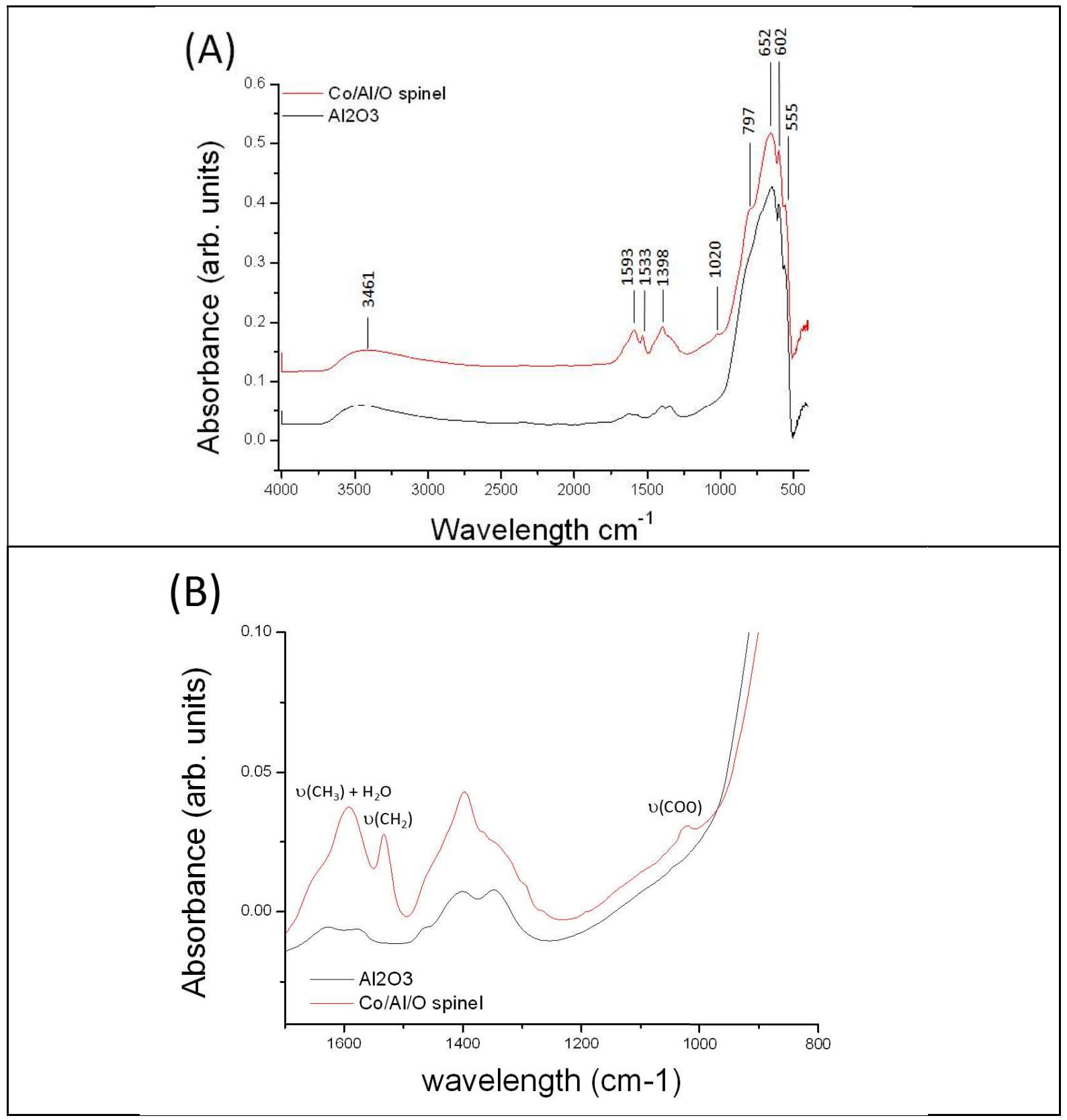

Figure 3. FTIR spectra of as-synthesized $\mathrm{Co}-\mathrm{Al}$ spinel nanoparticles and $\mathrm{Al}_{2} \mathrm{O}_{3}$ powder produced with FSP 

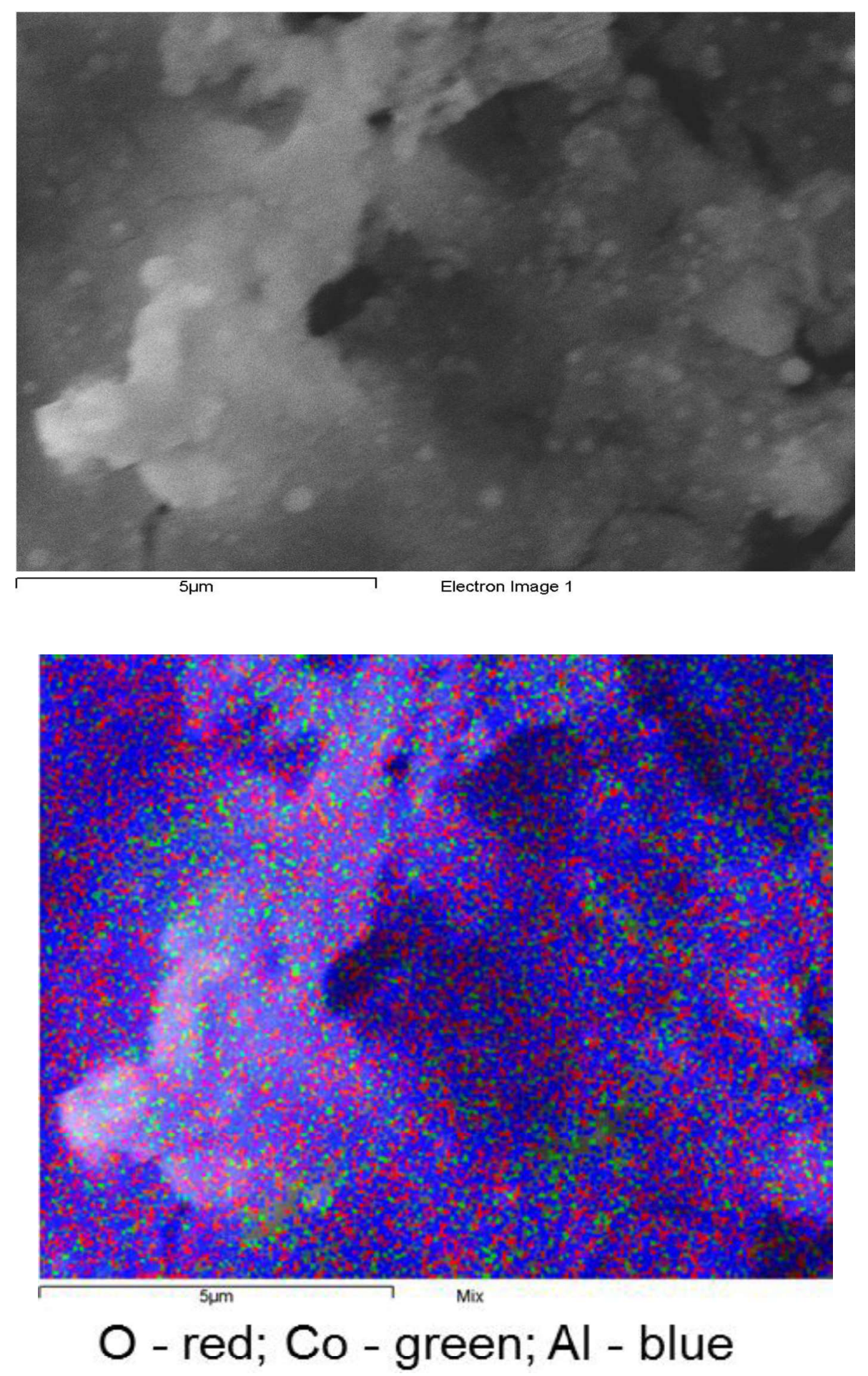

Figure 4. SEM images with elemental mapping of total components. 


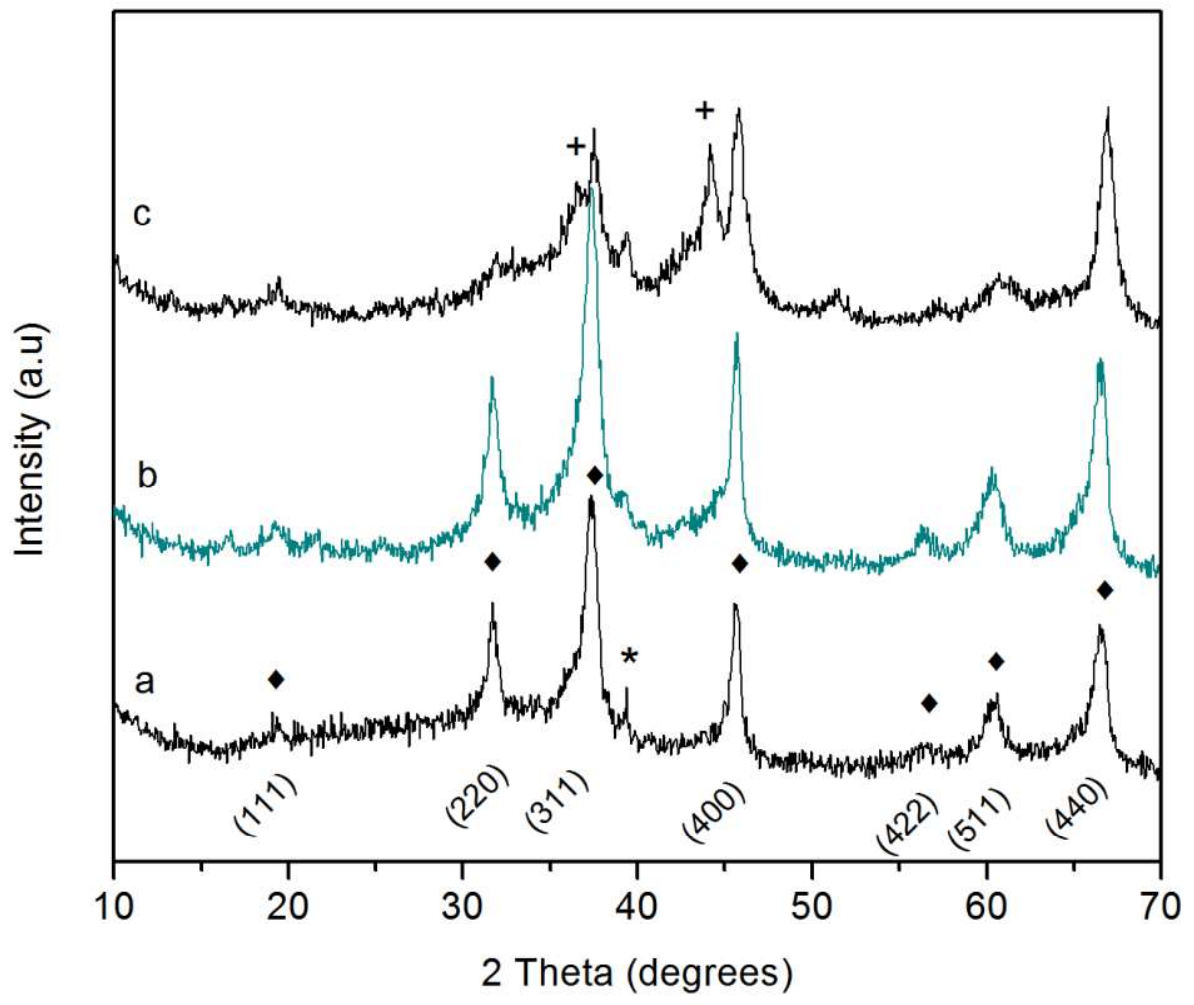

Figure 5. XRD patterns of the cobalt catalyst: (a) as-synthesized, (b) reduced at $723 \mathrm{~K}$, and (c) reduced at $1123 \mathrm{~K}$. = cobalt aluminum oxide species $\left(\mathrm{Co}_{2} \mathrm{AlO}_{4}, \mathrm{Fd}-3 \mathrm{~m}-(227)\right)$. *= gamma alumina $\left(\gamma-\mathrm{Al}_{2} \mathrm{O}_{3}\right)$ and $+=$ cobalt bearing face centered cubic structure (FD-3m- ( 225)). 

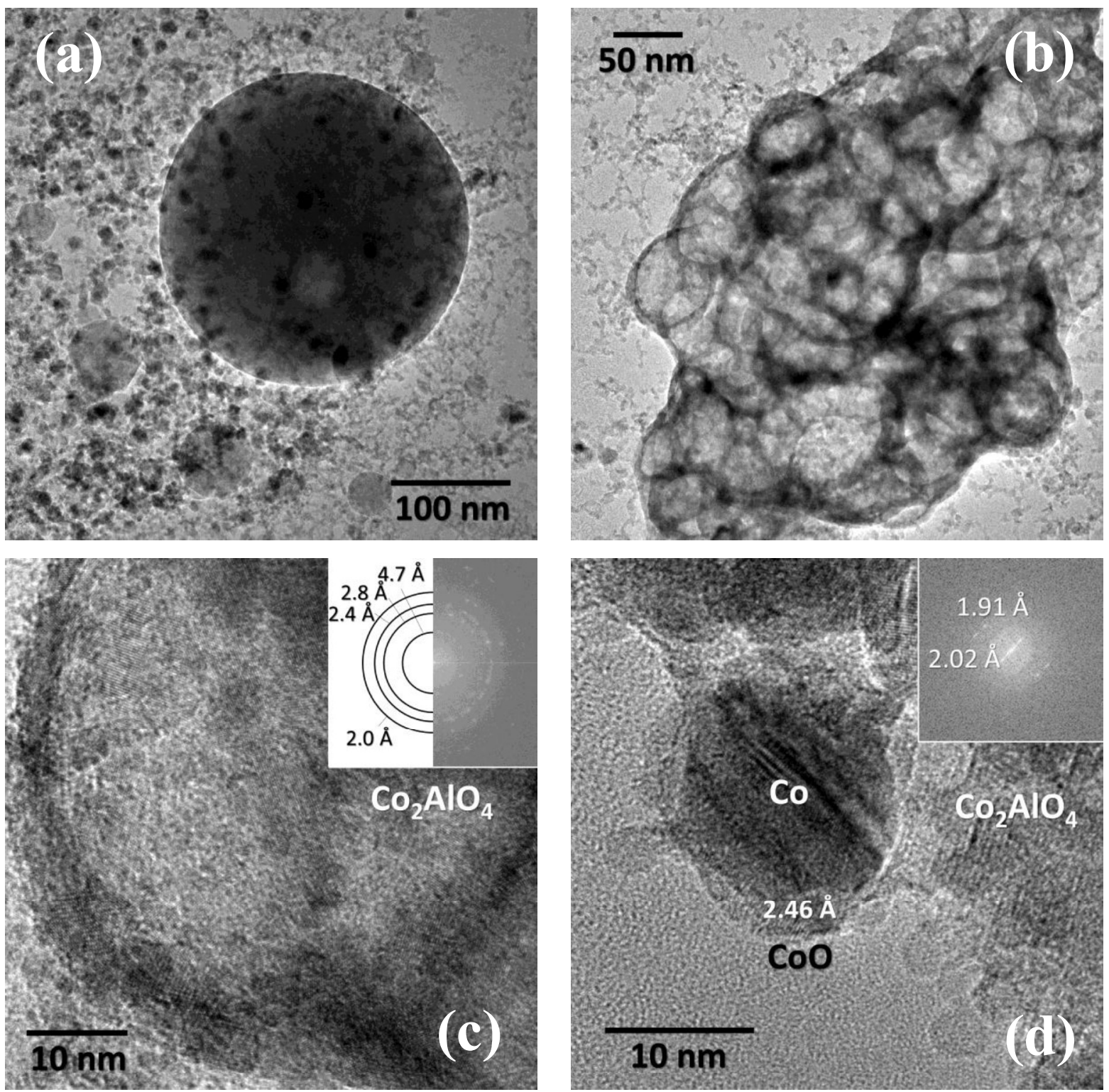

Figure 6. HRTEM images of the Co-Al spinel nanoparticles reduced at $1123 \mathrm{~K}$ for 4 hours. 

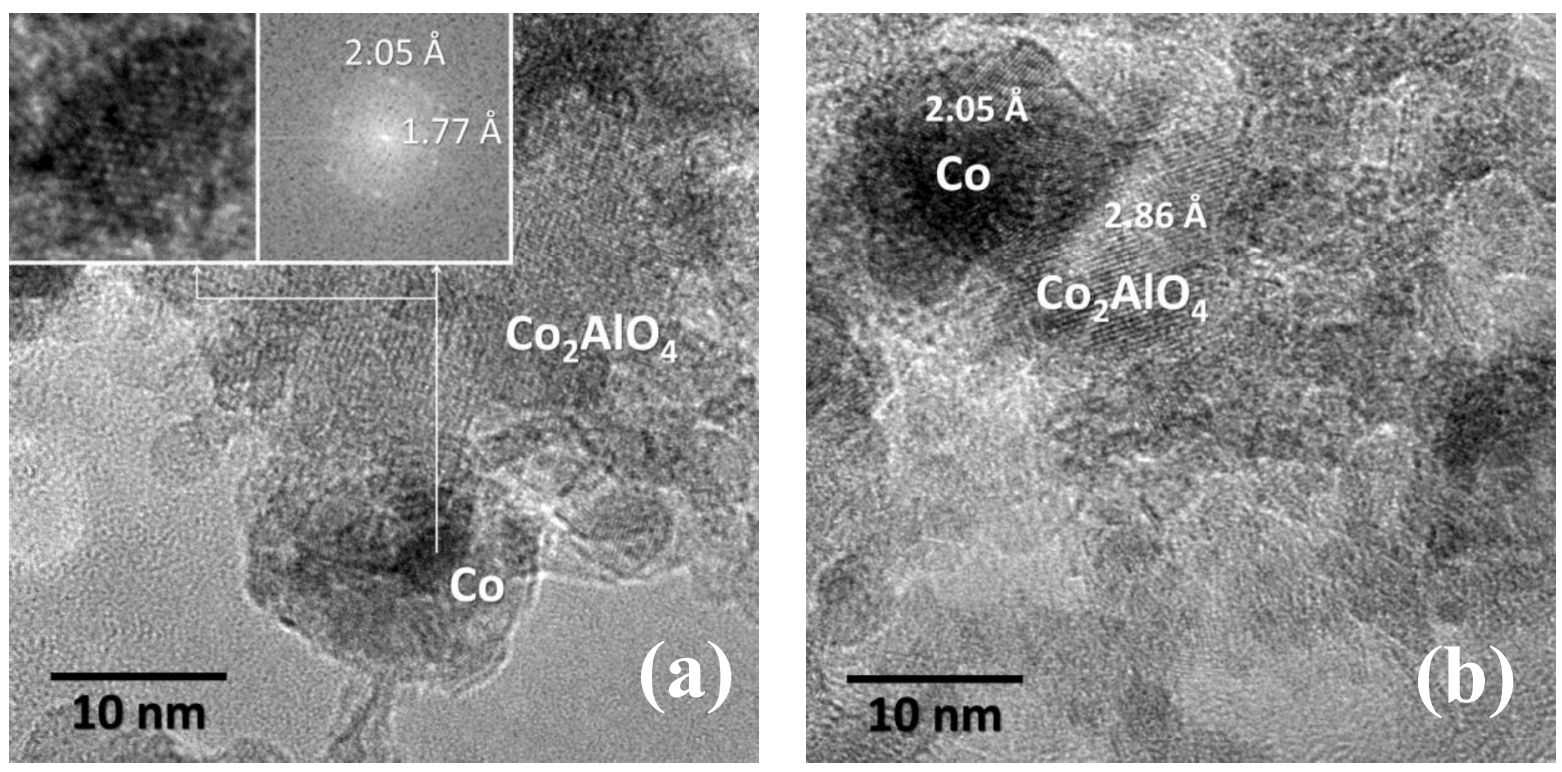

Figure 7. HRTEM of cobalt nanoparticles encountered both in hexagonal and cubic structures. 


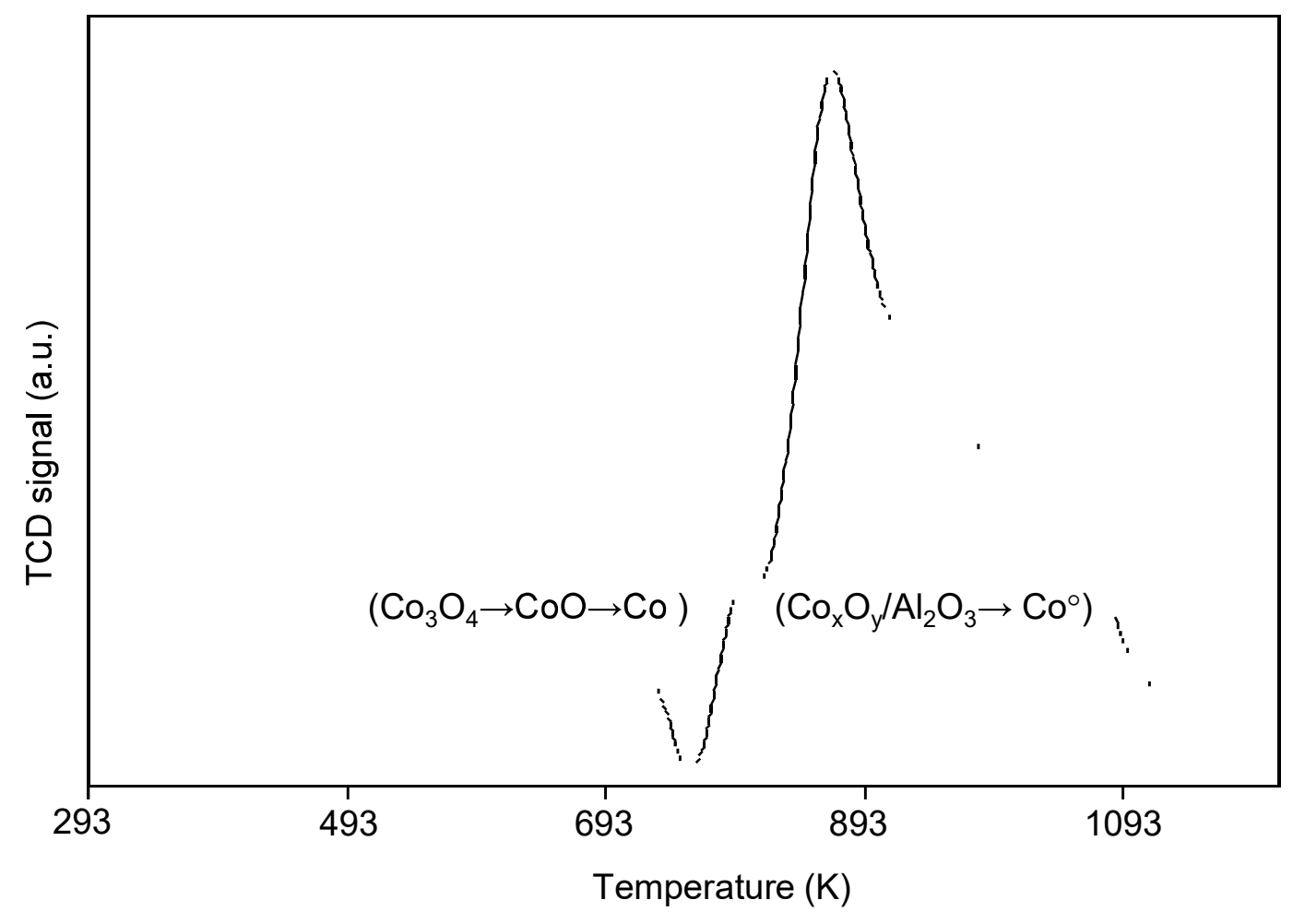

Figure 8. TPR profile of the Co-Al spinel nanoparticles. 


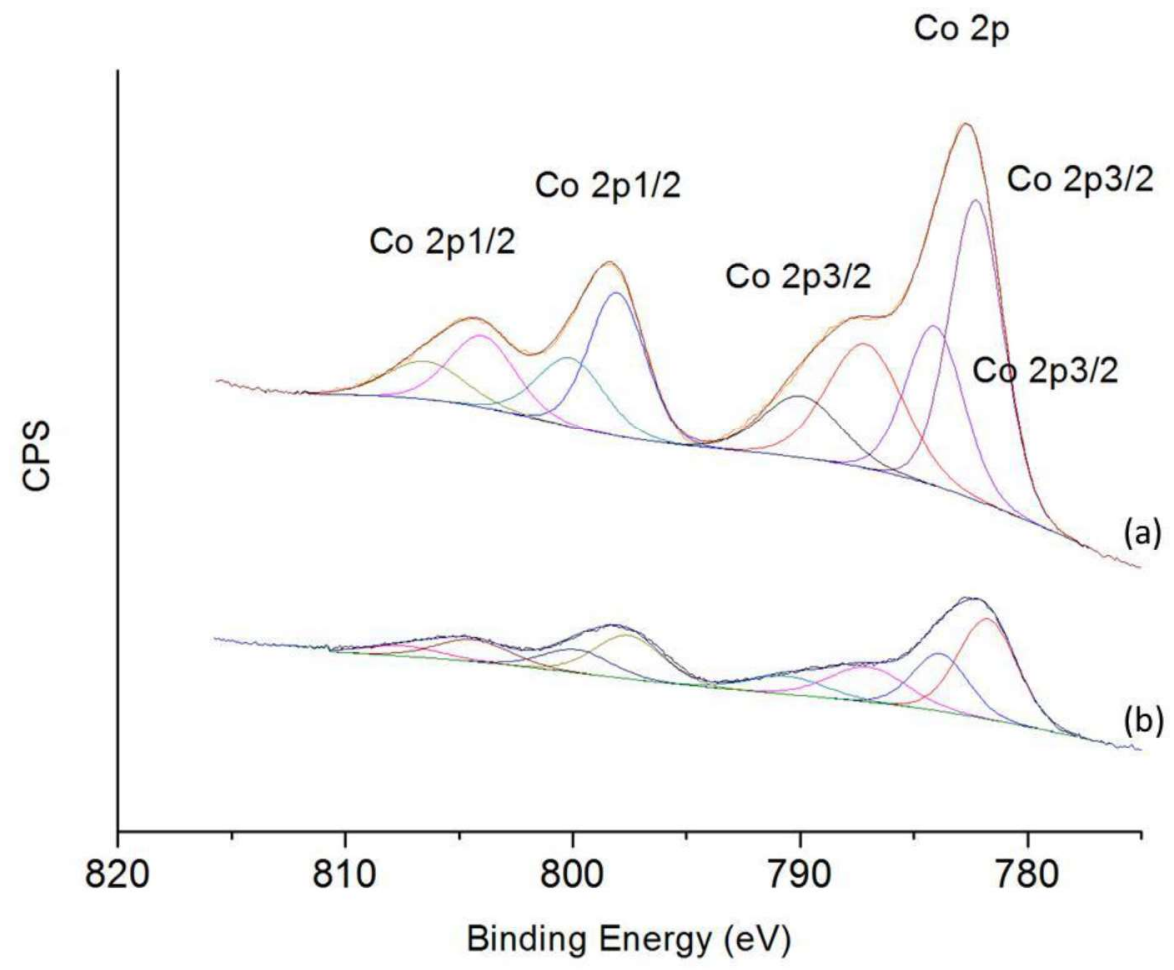

Figure 9. XPS spectra. (a) As-synthesized Co-Al spinel nanoparticles and the spectra (b) CoAl spinel nanoparticles reduced at $1123 \mathrm{~K}$ 

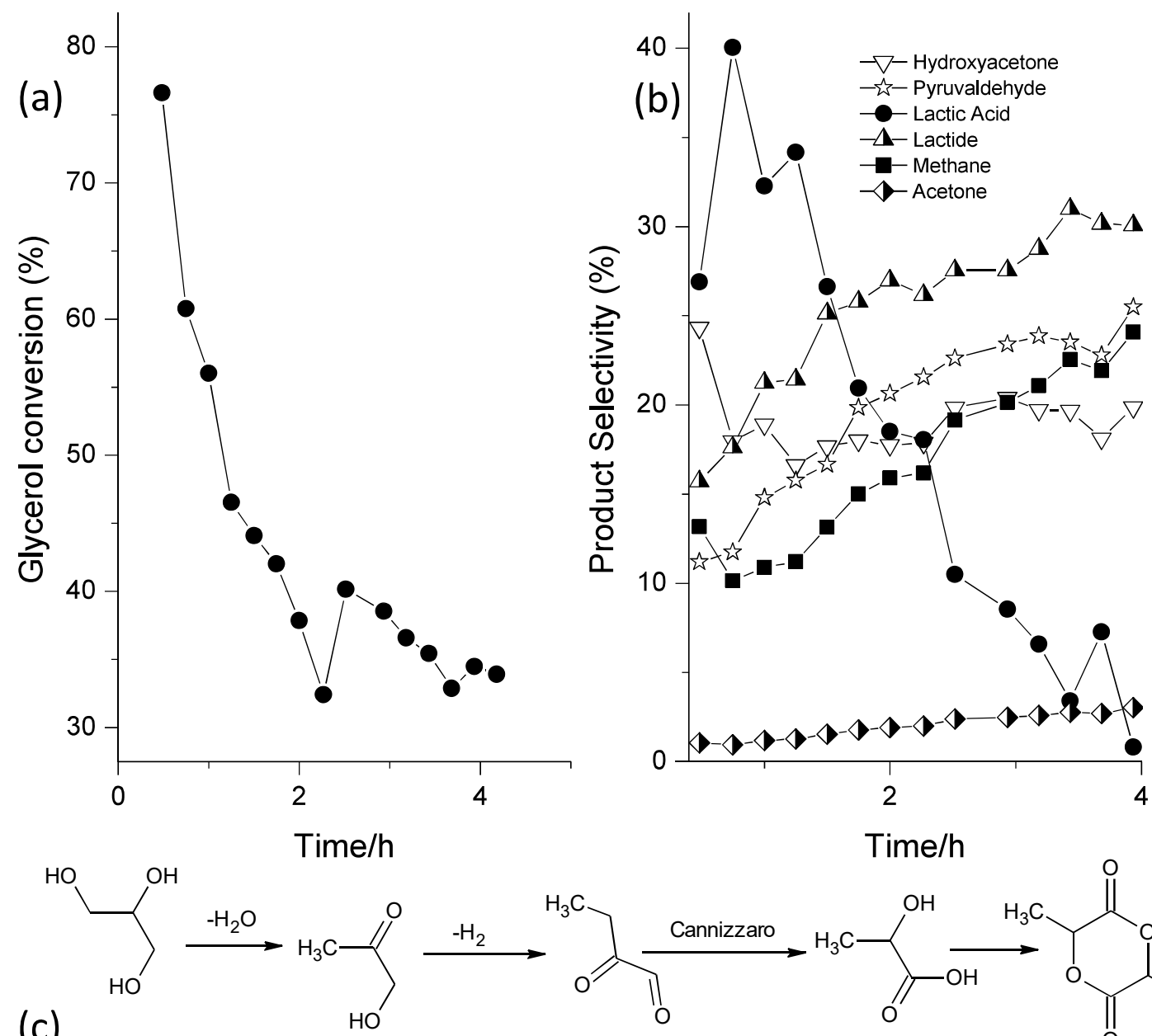

(c)

Glycerol Hydroxyacetone

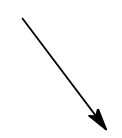

$\mathrm{CH}_{4}$

Methane

Figure 10. Conversion of glycerol and product selectivity as a function of time of reaction. 


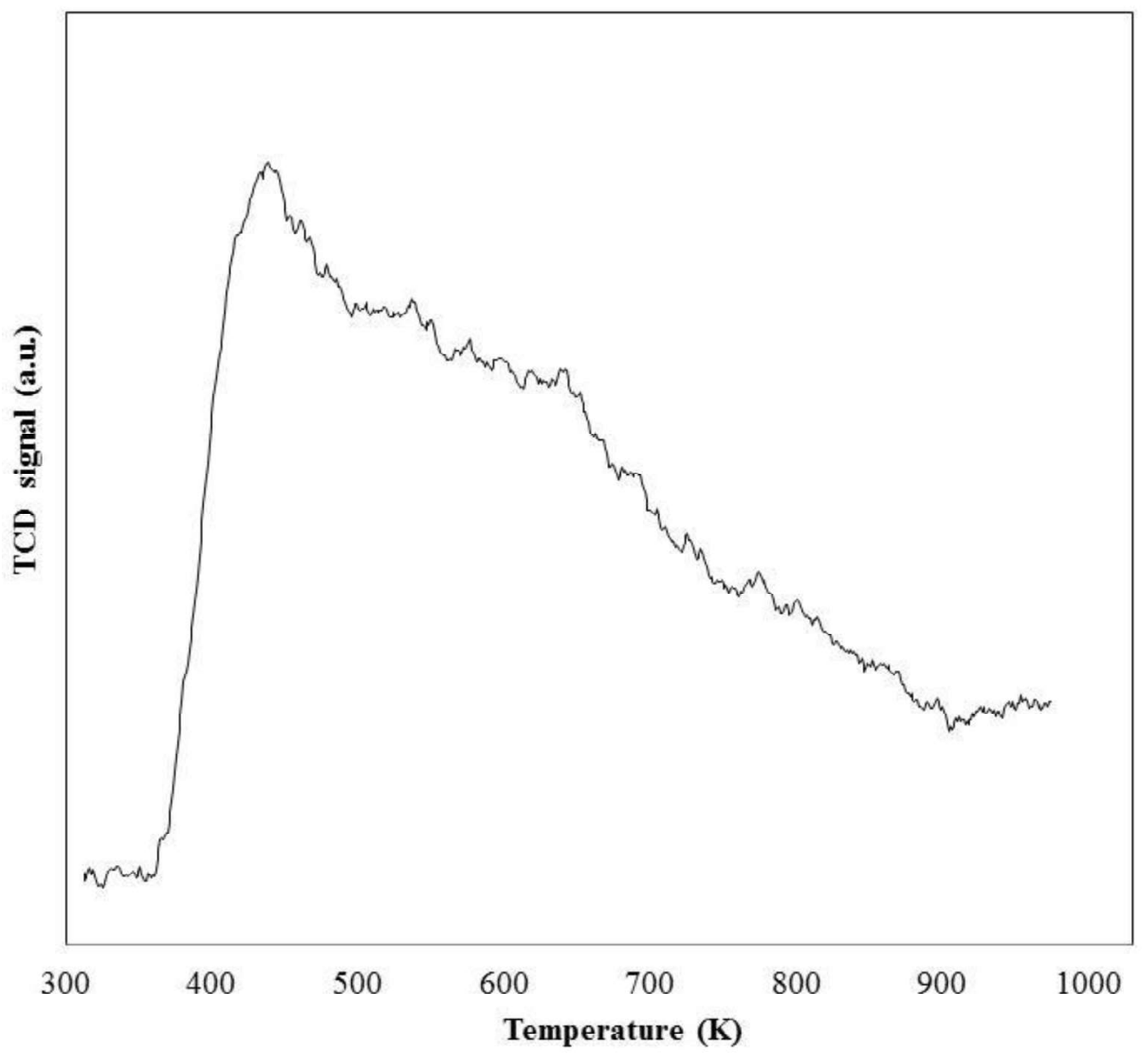

Figure 11. Temperature programmed desoption (TPD) of $\mathrm{NH}_{3}$ of the Co-Al spinel nanoparticles reduced at $1123 \mathrm{~K}$. 


\section{Caption to tables}

Table $1 . \mathrm{N}_{2}$ physisorption of the as-synthesized Co-Al spinel nanoparticles and Co-Al spinel nanoparticles reduced at $1123 \mathrm{~K}$.

\begin{tabular}{cccc}
\hline Sample & $\begin{array}{c}\mathrm{S}_{\mathrm{BET}} \\
\left(\mathrm{m}^{2} / \mathrm{g}\right)\end{array}$ & $\begin{array}{c}\text { Pore volume } \\
\left(\mathrm{cm}^{3} / \mathrm{g}\right)\end{array}$ & $\begin{array}{c}\text { Average pore } \\
\text { diameter }(\mathrm{nm})\end{array}$ \\
\hline $\begin{array}{c}\text { as-synthesized Co-Al } \\
\text { spinel nanoparticles }\end{array}$ & 174 & 1.21 & 3.73 \\
$\begin{array}{c}\text { Co-Al spinel } \\
\text { nanoparticles Reduced at } \\
1123 \mathrm{~K}\end{array}$ & 112 & 0.68 & 3.69 \\
\hline
\end{tabular}

Table 2. Elemental composition of the as-synthesized Co-Al spinel nanoparticles determined with energy dispersive X-ray spectroscopy (EDS)

\begin{tabular}{ccc}
\hline Element & Weight & Atomic \% \\
\hline $\mathrm{C}$ & 5.32 & 10.09 \\
$\mathrm{O}$ & 33.46 & 47.67 \\
$\mathrm{Al}$ & 37.03 & 31.28 \\
$\mathrm{Co}$ & 20.39 & 7.89 \\
$\mathrm{Si}$ & 3.79 & 3.08 \\
\hline
\end{tabular}

Table 3. Composition of the fresh and reduced particles determined with EDS. $\mathrm{CoAl}_{2} \mathrm{O}_{4}$ assyn: as-synthesized material; $\mathrm{CoAl}_{2} \mathrm{O}_{4}$ red: material reduced at $1123 \mathrm{~K}$ for $4 \mathrm{~h}$.

\begin{tabular}{ccc}
\hline Sample Id & Name & \%At Conc \\
\hline $\mathrm{CoAl}_{2} \mathrm{O}_{4}$ as-syn & $\mathrm{O} 1 \mathrm{~s}$ & 68.5 \\
$\mathrm{CoAl}_{2} \mathrm{O}_{4}$ as-syn & $\mathrm{Al} 2 \mathrm{p}$ & 24.9 \\
$\mathrm{CoAl}_{2} \mathrm{O}_{4}$ as-syn & $\mathrm{Co} 2 \mathrm{p}$ & 6.6 \\
\hline $\mathrm{CoAl}_{2} \mathrm{O}_{4}$ red & $\mathrm{O} 1 \mathrm{~s}$ & 72.5 \\
$\mathrm{CoAl}_{2} \mathrm{O}_{4}$ red & $\mathrm{Al} 2 \mathrm{p}$ & 24.8 \\
$\mathrm{CoAl}_{2} \mathrm{O}_{4}$ red & $\mathrm{Co} 2 \mathrm{p}$ & 2.7 \\
\hline
\end{tabular}


Table 4. The list of the binding energies (in eV) of Co2p obtained for the fresh and reduced particles with XPS. $\mathrm{CoAl}_{2} \mathrm{O}_{4}$ as-syn: as-synthesized material; $\mathrm{CoAl}_{2} \mathrm{O}_{4}$ red: material reduced at $1123 \mathrm{~K}$ for $4 \mathrm{~h}$.

\begin{tabular}{cccc}
\hline Sample Id & Name & Position & $\begin{array}{c}\text { \% Atomic } \\
\text { fractions }\end{array}$ \\
\hline $\mathrm{CoAl}_{2} \mathrm{O}_{4}$ as-syn & $\mathrm{Co} 2 \mathrm{p} 3 / 2$ & 782.3 & 20.4 \\
$\mathrm{CoAl}_{2} \mathrm{O}_{4}$ as-syn & $\mathrm{Co} 2 \mathrm{p} 3 / 2$ & 784.1 & 11.6 \\
$\mathrm{CoAl}_{2} \mathrm{O}_{4}$ as-syn & $\mathrm{Co} 2 \mathrm{p} 3 / 2$ & 789.9 & 6.1 \\
$\mathrm{CoAl}_{2} \mathrm{O}_{4}$ as-syn & $\mathrm{Co} 2 \mathrm{p} 3 / 2$ & 787.1 & 12.1 \\
$\mathrm{CoAl}_{2} \mathrm{O}_{4}$ as-syn & $\mathrm{Co} 2 \mathrm{p} 1 / 2$ & 798.1 & 19.8 \\
$\mathrm{CoAl}_{2} \mathrm{O}_{4}$ as-syn & $\mathrm{Co} 2 \mathrm{p} 1 / 2$ & 800.1 & 11.3 \\
$\mathrm{CoAl}_{2} \mathrm{O}_{4}$ as-syn & $\mathrm{Co} 2 \mathrm{p} 1 / 2$ & 804.0 & 11.6 \\
$\mathrm{CoAl}_{2} \mathrm{O}_{4}$ as-syn & $\mathrm{Co} 2 \mathrm{p} 1 / 2$ & 806.5 & 7.1 \\
\hline $\mathrm{CoAl}_{2} \mathrm{O}_{4}$ red & $\mathrm{Co} 2 \mathrm{p} 3 / 2$ & 781.8 & 22.2 \\
$\mathrm{CoAl}_{2} \mathrm{O}_{4}$ red & $\mathrm{Co} 2 \mathrm{p} 3 / 2$ & 783.8 & 11.9 \\
$\mathrm{CoAl}_{2} \mathrm{O}_{4}$ red & $\mathrm{Co} 2 \mathrm{p} 3 / 2$ & 790.6 & 5.3 \\
$\mathrm{CoAl}_{2} \mathrm{O}_{4}$ red & $\mathrm{Co} 2 \mathrm{p} 3 / 2$ & 787.0 & 10.1 \\
$\mathrm{CoAl}_{2} \mathrm{O}_{4}$ red & $\mathrm{Co} 2 \mathrm{p} 1 / 2$ & 797.6 & 21.5 \\
$\mathrm{CoAl}_{2} \mathrm{O}_{4}$ red & $\mathrm{Co} 2 \mathrm{p} 1 / 2$ & 799.8 & 11.5 \\
$\mathrm{CoAl}_{2} \mathrm{O}_{4}$ red & $\mathrm{Co} 2 \mathrm{p} 1 / 2$ & 804.4 & 11.8 \\
$\mathrm{CoAl}_{2} \mathrm{O}_{4}$ red & $\mathrm{Co} 2 \mathrm{p} 1 / 2$ & 807.5 & 5.8 \\
\hline
\end{tabular}

Table 5. Product selectivity in the conversion of glycerol at $573 \mathrm{~K}$ and 3 hours of reaction with Co-Al spinel nanoparticles reduced at $1123 \mathrm{~K}$

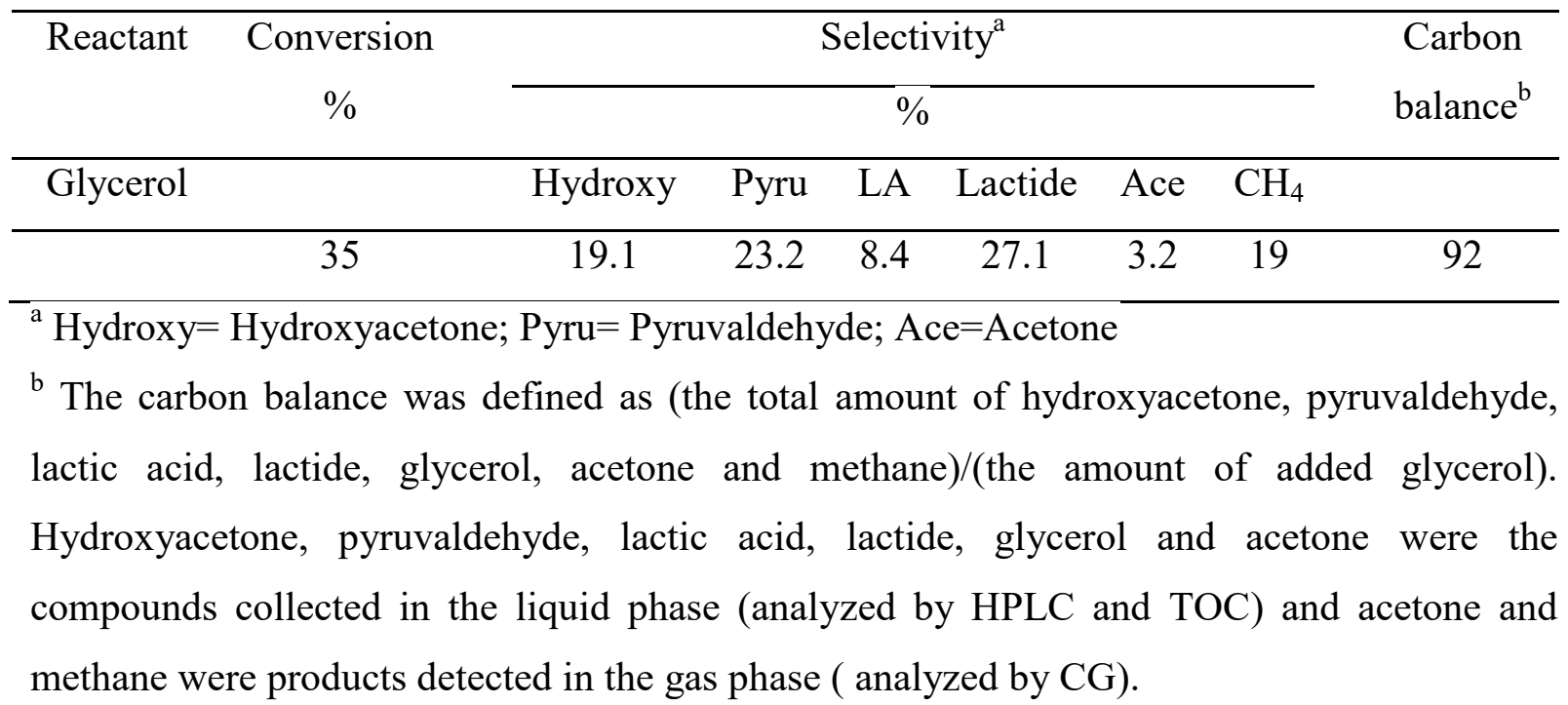


Table 6. $\mathrm{NH}_{3}$-TPD of the Co-Al spinel nanoparticles reduced at $1123 \mathrm{~K}$.

\begin{tabular}{|c|c|c|c|c|}
\hline \multirow{2}{*}{ Sample } & \multicolumn{2}{|c|}{$\begin{array}{c}\mathrm{NH}_{3} \text { desorption }(\mathrm{mmol} / \mathrm{g}) \\
(323-873 \mathrm{~K})\end{array}$} & \multirow{2}{*}{$\begin{array}{l}\text { Total } \mathrm{NH}_{3 \text { des. }} \\
\text { evolved } \\
(\mathrm{mmol} / \mathrm{g})\end{array}$} & \multirow{2}{*}{$\begin{array}{c}\text { Acid sites } \\
\text { density } \\
\left(\mu \mathrm{mol} / \mathrm{m}^{2}\right)\end{array}$} \\
\hline & $\begin{array}{c}\mathrm{I} \\
(\approx 473 \mathrm{~K})\end{array}$ & $\begin{array}{c}\text { II } \\
(\approx 623 \mathrm{~K})\end{array}$ & & \\
\hline $\begin{array}{c}\text { Co-Al spinel } \\
\text { nanoparticles } \\
\text { Reduced at } 1123 \mathrm{~K}\end{array}$ & $0.27(156)$ & $0.38(326)$ & 0.65 & 5.8 \\
\hline
\end{tabular}

In brackets: temperature maximum. 
Click here to download Supplemental Data: Supporting Information.docx 


\section{Highlights}

$\checkmark$ The FSP was crucial to obtain well-dispersed cobalt mixed oxide nanoparticles

$\checkmark$ The reduction step contributes to modulate the catalytic activity of the material $\checkmark$ The glycerol catalytic conversion produced commodity chemicals 


\section{Graphical Abstract}

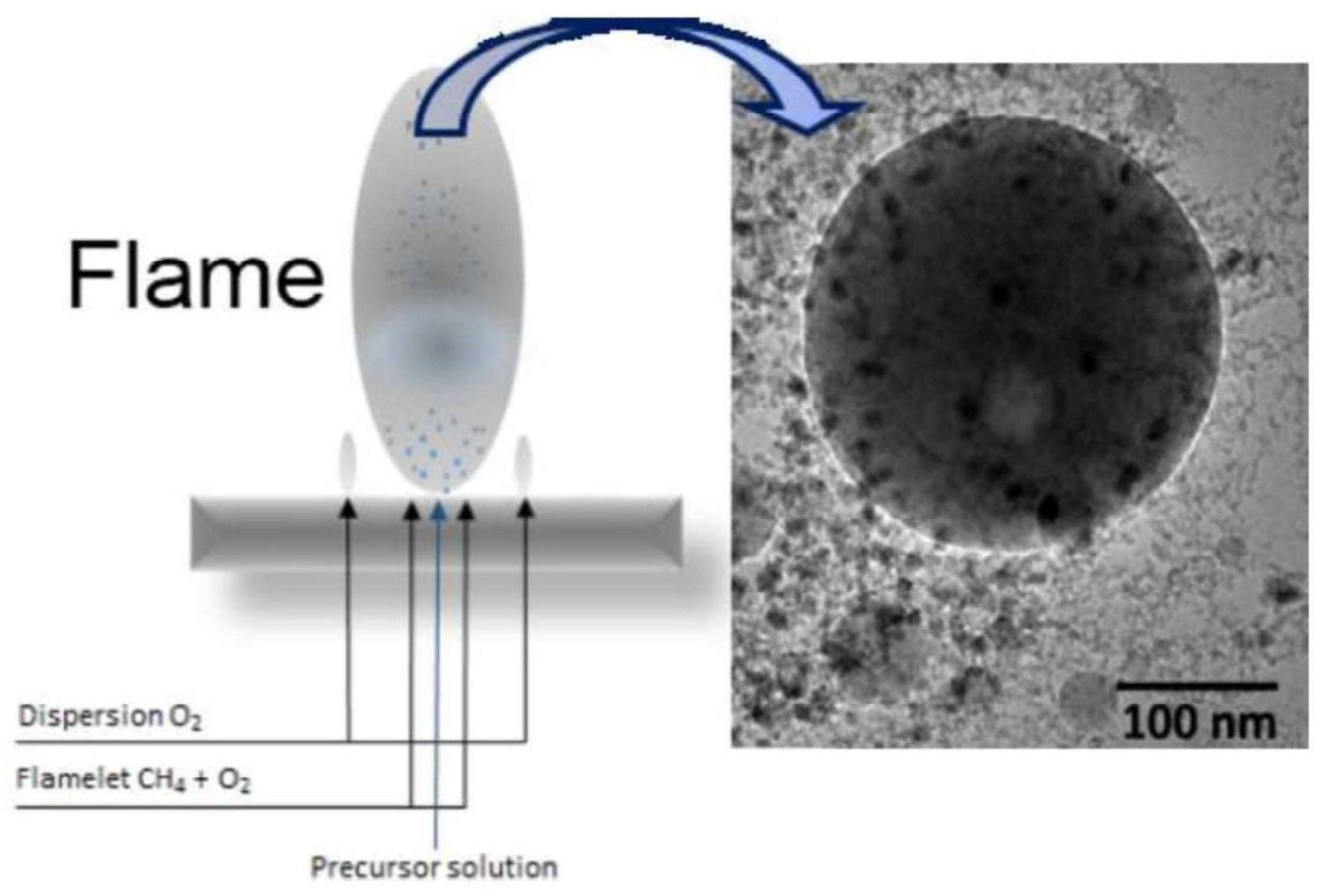

